\title{
The carbon economics of vegetative phase change: why plants make juvenile and adult leaves
}

Erica Lawrence ( $\square$ lawrence.erica.h@gmail.com )

University of Pennsylvania https://orcid.org/0000-0002-0220-3210

\section{Clint Springer}

Saint Joseph\&\#39;s University

\section{Brent Helliker}

University of Pennsylvania

Scott Poethig

University of Pennsylvania

\section{Article}

Keywords:

Posted Date: April 22nd, 2021

DOI: https://doi.org/10.21203/rs.3.rs-448939/v1

License: (c) (1) This work is licensed under a Creative Commons Attribution 4.0 International License.

Read Full License 


\section{The carbon economics of vegetative phase change: why plants make juvenile and adult}

2 leaves

3 Authors: Erica H. Lawrence ${ }^{1}$, Clint J. Springer ${ }^{2}$, Brent R. Helliker ${ }^{1}$ and R. Scott Poethig ${ }^{1}$

$5{ }^{1}$ Department of Biology, University of Pennsylvania, 433 S. University Ave, Philadelphia,

6 Pennsylvania, 19104 USA

$7{ }^{2}$ Department of Biology, Saint Joseph’s University, 5600 City Ave, Philadelphia, Pennsylvania, 819131 USA

\section{Abstract}

Across plant species and biomes, a conserved set of leaf traits govern the economic strategy used to assimilate and invest carbon. As plants age, they face new challenges that may require shifts in this leaf economic strategy. In this study, we investigate the role of the developmental transition, vegetative phase change (VPC), in altering carbon economics as plants age. We used overexpression of miR156, the master regulator of VPC, to modulate the timing of VPC in Populus tremula x alba, Arabidopsis thaliana and Zea mays to understand the impact of this transition on leaf economic traits, including construction cost, payback time, and return on investment. Here we find that VPC regulates the shift from a low-cost, quick return juvenile strategy to a high-cost, high-return adult strategy. The juvenile strategy is advantageous in light-limited conditions, whereas the adult strategy provides greater returns in high-light. The transition between these strategies is correlated with the developmental decline in the level of miR156, suggesting that is regulated by the miR156/SPL pathway. Our results provide an eco-physiological explanation for the existence of juvenile and adult leaf types, and suggest that natural selection for these alternative economic strategies could be an important factor in plant evolution.

\section{Introduction}

In the plant world carbon is queen. It is the currency with which they build, barter and operate. Plants acquire this resource through the enzymatic reactions of photosynthesis which harnesses light energy from the sun to convert $\mathrm{CO}_{2}$ into sugars. In order to succeed, plants must photosynthesize efficiently and carbon must be invested wisely. 
Leaves are the primary organ through which photosynthesis occurs, and as such, variations in leaf traits that alter carbon economic strategies are of great interest. Leaf construction costs, the amount of carbon required to build leaves, as well as their returns on investment (ROI), determine the resources available for growth and reproduction. Construction cost and ROI are influenced by the morphological and physiological traits that determine leaf chemical composition, photosynthetic capacity (represented by light saturated photosynthetic rate, $A_{\text {sat }}$ ), respiration $\left(\mathrm{R}_{\mathrm{d}}\right)$, and leaf lifespan (Poorter, 1994; Poorter et al., 2006). Plants across the globe share conserved relationships between these morphological and physiological traits, creating what is known as the worldwide leaf economics spectrum (LES) (Wright et al., 2004).

The LES uses leaf traits to describe economic strategies ranging from low investment yielding quick returns, to high investment yielding slow returns. Central to the LES is leaf mass per area (LMA), or its inverse specific leaf area (SLA), which describe ratios between leaf area and mass that quantify changes in leaf thickness and density. Often, the high LMA associated with thicker, denser leaves leads to greater proportions of structural tissue that results in a greater construction cost but also longer leaf lifespan (Reich et al., 1992; Poorter et al., 2009). Because of differences in light interception and proportions of photosynthetic tissues, high LMA leaves also tend to have lower mass-based $\mathrm{A}_{\text {sat }}$, leading to a high investment, slow-return economic strategy, with the opposite being true for leaves with low LMA (Terashima \& Hikosaka, 1995; Reich et al., 1998; Wright et al., 2004; Terashima et al., 2006). Of course, ROI is not directly tied to these strategies as longer lifespan and faster payback of initial cost both have the potential to lead to greater photosynthetic outputs.

While largely ignored, ontogenetic variation in leaf economic strategies is equal in magnitude to that between species (Mason et al., 2013; Hayes et al., 2019; Funk et al., 2020). Shifts in leaf traits from those associated with quick-return to longer-return economic strategies are consistently observed with increasing plant age. Further, trait-trait relationships (i.e. the magnitude with which leaf lifespan increases in response to increasing LMA) are significantly

58 altered across plant development, akin to the alterations induced by environment (Niinemets, 2004; Damián et al., 2018; Liu et al., 2019; Funk et al., 2020). These shifts in leaf traits likely have significant ecological impacts altering plant growth, resource acquisition, and

61 environmental interactions across its lifespan. 
Plant ontogeny includes the juvenile-to-adult vegetative transition known as vegetative

63 phase change (VPC). VPC and its master regulator, microRNA156, have been conserved across

64 plant evolution (Axtell \& Bowman, 2008). However, the functional significance of this

65 transition, and its impacts on fitness remains a major question in plant developmental biology.

66 As plants progress from the juvenile to adult vegetative phases, the variations in challenges and

67 resources available likely command distinct economic strategies. Previously, we showed that

68 VPC and miR156 modulates morphological and physiological traits central to carbon economics

69 (Lawrence et al., 2020). Specifically, the changes in miR156 expression that drive VPC alter

70 SLA, leaf $\mathrm{N}$ and photosynthetic rates across species. miR156-mediated decreases in SLA

71 (equivalent to increases in LMA) between juvenile and adult phases are consistent with the shift

72 from quick to long-return economic strategies previously described. This suggests miR156 is a

73 regulator of ontogenetic changes in leaf carbon economics and that VPC, and the timing of this

74 developmental transition, has important implications for changes in resource use strategies

75 deployed across a plant's lifespan. As a genetically programmed transition, VPC may impact

76 plant fitness by allowing plants to shift between economic strategies as their physiological

77 demands change with age.

78 In this study we used wildtype and miR156 overexpressor mutants in three diverse 79 species, Arabidopsis thaliana, Populus tremula $x$ alba, and Zea mays, to investigate how VPC---

80 which is driven by a decline in miR156 expression - is related to ontogenetic shifts in carbon

81 economic strategies. We demonstrate that the previously identified phase-specific changes in leaf

82 morphology and photosynthetic physiology lead to shifts from quick to slow-return economic

83 strategies, and further show that these strategies are likely to be adaptive under different light

84 environments. The evidence that ontogenetic changes in leaf carbon economics are under the

85 regulation of miR156 not only provides a molecular mechanism for this transition in leaf

86 physiology, but also provides an eco-physiological rationale for the existence of vegetative phase 87 change.

\section{Results}

90 Construction cost is higher for adult than juvenile or juvenilized leaves

91 The chemical composition of adult, juvenile and juvenilized leaves in three test species

92 was determined in order to understand how VPC contributes to leaf construction costs. By using 
93 juvenilized leaves in miR156 overexpressor lines (those with a juvenile phenotype at leaf

94 positions that would normally be adult), we are able separate the effects of VPC from those

95 related to plant size or age. If a measured trait is developmentally phase-specific, juvenilized

96 leaves at "adult" nodes should be more similar to juvenile leaves than to adult leaves. Per gram

97 of leaf tissue, adult, juvenile and juvenilized leaves require the same amount of glucose ( $p>$

98 0.05, Fig. 1A-B) in P. tremula $x$ alba and A. thaliana; thus the composition of leaves is similar

99 across development (Table 1). One exception to this similarity was the concentration of nitrate in

100 A. thaliana leaves, which was greater in developmentally juvenile leaves $(p<0.05)$. In Z. mays,

101 adult leaves have a greater construction cost per gram of tissue than juvenile and juvenilized

102 leaves due to phase-specific differences in carbon, nitrogen, and mineral concentrations ( $p<$

103 0.05) (Fig. 1C, Table 1).

104 At the whole leaf level, adult leaves of all three species cost significantly more $(p>0.05)$

105 glucose to construct than their juvenile and juvenilized counter parts (Fig. 1D-F). This phase-

106 specific pattern is observed even in P. tremula $x$ alba and $A$. thaliana where there are no

107 differences in cost per gram of leaf tissue, due to the significantly greater area and mass of adult

108 leaves compared to both juvenile and juvenilized leaves $(p>0.05)$ (Table S1). Overall, we find

109 that regardless of differences in chemical composition, the effect of VPC on leaf size leads to

110 higher costs for adult compared to juvenile leaves.

112 Leaf payback time becomes longer as plants transition from juvenile to adult, but the difference

113 in magnitude depends on light environment.

114 Payback time, the amount of time it takes for a leaf to assimilate the carbon originally

115 invested in its construction, is greater for adult leaves than juvenile or juvenilized leaves across

116 all light levels for all three test species (Fig. 2A-C). Interestingly, there is a significant

117 interaction between developmental phase and light $(p<0.05)$ in all three species as the

118 difference between developmental phases is greater as light decreases. Specifically, adult leaves

119 of $P$. tremula $x$ alba have, respectively, 7.85 and 3.4 fold longer payback time than juvenile and

120 juvenilized leaves under low-light $\left(10 \mu \mathrm{mol} \mathrm{m}^{2} \mathrm{~s}^{-1}\right)$, but only 6.6 and 1.79 fold longer payback

121 time under high-light $\left(1000 \mu \mathrm{mol} \mathrm{m}^{2} \mathrm{~s}^{-1}\right)$. In A. thaliana, the payback time for adult leaves is,

122 respectively, 18.8 and 5.7 fold longer under low-light, and 9.4 and 3.16 fold longer under high-

123 light, than for juvenile and juvenilized leaves. Lastly, in Z. mays, adult leaves have, respectively, 
1248.13 and 11.64 fold longer payback time under low-light, and 6.3 and 12 fold longer payback

125 time under high-light than juvenile and juvenilized leaves. Because construction cost remains

126 constant across light levels in our modeled payback time, these differences are a result of

127 photosynthetic responses to light modeled using light response curves (Table S2). Similar

128 relationships between payback time and light are observed on a per gram basis for all three

129 species, although to a lesser extent (Fig. S1). As we saw with construction costs, the greater

130 similarity between juvenilized leaves with juvenile, as opposed to adult leaves, indicates

131 differences in miR156-mediated development, rather than plant size or age, is responsible for the

132 payback differences observed here.

Leaf lifespan is longer for adult leaves than juvenile leaves

To understand how phase-specific differences in leaf construction cost and payback time

136 impact the overall economic strategy of juvenile and adult leaves, we also measured the

137 photosynthetic lifespan of these leaves. Previously, we determined that SLA, which is closely

138 connected to lifespan, is a phase-specific trait, with adult leaves having lower SLA (or higher

139 LMA) compared to both juvenile and juvenilized leaves of all three test species (Table S1,

140 Lawrence et al., 2020b). Across species, thicker, more dense adult leaves (low SLA) had

141 significantly longer $(p<0.05)$ lifespans than juvenile leaves (Fig. 2D-F). Lifespan differences

142 between juvenile and adult leaves ranged from 26 and 23 days in P. tremula $x$ alba and Z. mays,

143 respectively, to 8 days in $A$. thaliana. Of note, the low-light payback time for adult Z. mays

144 leaves (which approaches 52 days) far exceeds the 34-day average lifespan of these leaves.

\section{Light environment alters the phase-specific relationship of leaf return on investment}

Despite higher construction cost and longer payback time, lifespan differences produce a

148 higher return on investment (ROI) for adult leaves than for juvenile leaves, across most light

149 environments (Fig. 2G-I). Adult leaves outperform juvenile leaves in high-light environments

$150\left(1000 \mu \mathrm{mol} \mathrm{m}^{2} \mathrm{~s}^{-1}\right)$ with 14, 2.8 and 18 times more glucose returns for P.tremula $x$ alba, $A$.

151 thaliana and Z. mays respectively. However, in low-light environments $\left(10 \mu \mathrm{mol} \mathrm{m}^{2} \mathrm{~s}^{-1}\right)$, adult

152 leaves experience net carbon loss with 4.3, 4.6 and 5.1 times fewer returns than juvenile leaves.

153 Furthermore, the ROI for juvenile leaves is less sensitive to light environment than is the case for

154 adult leaves. Juvenile leaves approach their maximum ROI at a PPFD around $10 \mathrm{~mol} \mathrm{~m}^{-2} \mathrm{day}^{-1}$ 
155 whereas, with the exception of $A$. thaliana, which was grown under low-light conditions for this

156 experiment, the ROI for adult leaves continues to increase as PPFD increases, well past $40 \mathrm{~mol}$

$157 \mathrm{~m}^{-2}$ day $^{-1}$. ROI per gram of tissue display similar patterns across light environments to leaf-based

158 measures in P. tremula $x$ alba and Z. mays. However, in A. thaliana, juvenile tissue maintains a

159 higher ROI than adult tissue across all light environments (Fig. S1).

Photosynthetic induction is faster in juvenile leaves than in adult leaves

Because light levels continuously fluctuate throughout the day in forests and crop fields

163 (i.e. from the sun moving across the sky, leaves fluttering in the wind, etc.), modeling carbon

164 economics of $P$. tremula $x$ alba and Z. mays under more realistic conditions required an analysis

165 of the rate of photosynthetic induction in juvenile and adult leaves. Upon exposure to saturating

166 light, juvenile leaves of both species more quickly reached higher photosynthetic rates and

167 induction states than adult leaves (Fig. 3). The relaxation times for Rubisco activation were not

168 significantly different $(\mathrm{p}<0.05)$ between juvenile and adult leaves (Table S3), indicating that

169 developmental differences in induction occur prior to $1 \mathrm{~min}$, during the 'fast-phase' of induction.

170 Alternatively, developmental differences in induction could be due to a combination of

171 traits, such as stomatal conductance and Calvin cycle intermediate accumulation, rather than

172 solely to the activation of Rubsico. In P. tremula $x$ alba, differences in photosynthetic induction

173 are apparent by 1 min of high-light exposure, suggesting phase-specific differences in induction

174 are likely present before exposure to high-light, or during the first minute, when buildup of

175 intermediates in the Calvin cycle are most important. This is not the case for Z. mays, where

176 juvenile leaves reach a higher induction state than adult leaves during this 'slow-phase' period of

177 minutes 1-10 (Fig. 3D). These results suggest that while juvenile leaves of both species have

178 faster photosynthetic induction properties than their adult counter parts, the mechanisms behind

179 these differences may vary between species.

181 Dynamic light models show phase-specific leaf economic relationships are more dependent on

182 daily light than number of sunflecks

183 For both P. tremula $x$ alba and Z. mays, the dynamics of light environment had a

184 significant effect $(p<0.05)$ on the relationship of payback time and ROI between juvenile and

185 adult leaves (Fig. 4A,C, Fig. 5A,C). Over 156 different light simulations, daily PPFD varied 
186 between 18 and $32 \mathrm{~mol} \mathrm{~m}^{-2}$ day $^{-1}$ while the number of sunflecks varied between 1 and 242

187 (figures of simulated light environments in Fig. S2). The carbon economic traits of adult leaves

188 were much more affected by PPFD compared to juvenile leaves, as indicated by the smaller

189 slope of the negative relationship with payback time, and the larger slope of the positive

190 relationship with ROI for adult leaves of both species (Table S4). Similar trends are observed on

191 a per gram of tissue basis, although differences between juvenile and adult leaf payback time

192 across PPFD are not significant $(p>0.05)$ for $P$. tremula $x$ alba (Fig. S3, Table S4).

193 Surprisingly, there was no significant interaction between developmental phase and 194 number of sunflecks for payback time or ROI in P. tremula $x$ alba (Fig. 4B,D)(Table S4). While 195 significant interactions $\left(p<0.05\right.$ ) were present for these relationships in $Z$. mays, the low $R^{2}$ 196 values for both developmental phases and economic traits $\left(R^{2} \leq 0.05\right)$, indicate that sunflecks 197 have a minor effect on payback time and ROI (Table S4). There were no significant differences

198 in the way juvenile and adult tissue responded to sunflecks on a per gram basis, and any

199 significant relationships between payback time or ROI and sunflecks for either developmental 200 stage was minor $\left(R^{2} \leq 0.05\right)$ (Fig. S3, S4, Table S4).

201 Despite there being no meaningful relationship between carbon economics and number of 202 sunflecks, lags in photosynthetic response to light fluctuations due to the rate of induction 203 resulted in assimilation loss for both developmental phases in both species. As the number of 204 sunflecks increased and plants were exposed to more rapid changes in light, the assimilation lost 205 due to a lag in induction also increased (Fig. 6). In both species, the faster induction rate in 206 juvenile leaves resulted in lower assimilation losses compared to adult leaves $(p<0.05)$.

207 Nevertheless, the impact of these losses on carbon economics in these simulated environments is 208 minimal compared to the effect of overall changes in PPFD.

\section{Discussion}

211 Vegetative phase change alters plant economic strategies through miR156-mediated 212 changes in leaf morphology and physiology. Juvenile leaves - which have high levels of 213 miR156 - use a low-cost, quick-return economic strategy, whereas adult leaves - which have 214 low levels of miR156 - use a high-cost, slow-return strategy. The adult strategy carries more 215 risk than the juvenile strategy, but has the potential to provide high ROI (Fig. 7). This 216 developmental shift in strategy is brought about by the same traits that govern leaf economics 
217 across species and environments in the LES, namely leaf lifespan and LMA (Wright et al.,

218 2004). Across species, adult leaves have high LMA and long lifespan while juvenile leaves have

219 low LMA and shorter lifespan (Fig. 2D-F, Table S1). In Z. mays, leaf N and the photosynthetic

220 rates of juvenile and adult leaves follow the established trait relationships within the LES as the

221 low LMA juvenile leaves also have higher mass-based measures of $\mathrm{N}$ and $\mathrm{A}_{\text {sat }}$ compared to adult

222 leaves (Table 1, Lawrence et al., 2020b). As previously reported, trait-trait relationships of the

223 LES are not always conserved at smaller than global scales (Edwards et al., 2014; Mason \&

224 Donovan, 2015b; Anderegg et al., 2018). We find this to be the case for developmental changes

225 in leaf $\mathrm{N}$ and $\mathrm{A}_{\text {sat }}$ in P. tremula $x$ alba and A. thaliana, as these leaves have no significant

226 differences in mass-based measures of $\mathrm{N}$ and $\mathrm{A}_{\text {sat }}$ despite their differences in LMA. It is unclear

227 why the expected negative relationships between LMA and leaf $\mathrm{N}$ or $\mathrm{A}_{\text {sat }}$ are lacking, as LMA

228 increases during VPC in these species. However, previous work found no phase-specific changes

229 in photosynthetic nitrogen use efficiency (PNUE) (Lawrence et al., 2020), indicating adult leaves

230 somehow compensate for the structural changes that often reduce PNUE in high LMA leaves,

231 potentially through their increased stomatal density which could reduce resistance to $\mathrm{CO}_{2}$

232 diffusion (Hikosaka, 2004; Feng et al., 2016; Lawrence et al., 2021).

233 These developmentally programmed changes in leaf carbon economic strategy are likely

234 to have ecological implications because plants face different biotic and abiotic challenges during

235 their lifetime. For example, juvenile leaves, which have a photosynthetic advantage over adult

236 leaves under low-light (Lawrence et al., 2020), are more likely to be found in low, highly

237 dynamic, light environments because young plants are often shaded by their neighbors, and

238 quickly self-shade due to their relatively rapid rate of leaf production (Wang et al., 2008). Here

239 we find that the economic strategy of juvenile leaves further adds to this low-light advantage as

240 these leaves are able to maintain a positive carbon balance even at very low light levels (Fig. 2,

241 7). The payback time of adult leaves dramatically increases under low-light, greatly reducing

242 ROI and, in some cases, exceeds the lifespan of a leaf, resulting in net carbon loss. On the other

243 hand, the magnitude with which adult ROI exceeds that of juvenile leaves increases significantly

244 with increasing irradiance (Fig. 2). Overall, the economic strategy of juvenile leaves appears to

245 be less sensitive to light environment, making it a low-risk, low-reward strategy that is likely

246 beneficial for a young plant with minimal carbon reserves. Although the high-cost strategy of 
adult leaves incurs greater risk because of long-term environmental variability, the high-reward potential of this strategy may outweigh this risk.

Surprisingly, the ability of juvenile leaves to respond more quickly to sunflecks than adult leaves had little effect on the carbon economic relationships between these leaves in our dynamic light models (Fig. 4,5). In our simulated environments, we held the total time leaves were exposed to sunflecks relatively constant but allowed the number of sunflecks to vary dramatically. As a result, there was no correlation between the number of sunflecks and daily integrated PPFD. It may be that developmental differences in induction rate have a greater influence on carbon economic relationships when sunflecks play a large role in determining daily PPFD, such as in a rainforest understory where sunflecks can account for $52 \%$ of daily light (Chazdon \& Pearcy, 1991).

The developmental differences in carbon economics described here indicate that genotypic variation in miR156 expression, and subsequently the timing of VPC, could have significant consequences for plant ecology and evolution. Among other things, leaf economic strategies alter plant growth and survival in response to nutrient and water availability,

262 herbivory, competition and light environment (Coley, 1988; Poorter et al., 2006; Reich, 2014;

263 Mason \& Donovan, 2015a; Russo \& Kitajima, 2016; Adams et al., 2020). That the

264 developmentally regulated changes in leaf economic strategy are conserved among juvenile and

265 adult leaves of three phylogenetically diverse species, and that this strategy confers the ability to

266 respond to changes in environmental factors, suggests these ontogenetic changes in carbon

267 economics are widely advantageous. A better understanding of natural variation in the timing of

268 VPC, and the function of this process in plant physiology and response to environmental

269 stressors, is crucial for determining the role of this developmental transition in plant ecology and 270 evolution.

272 Materials and Methods

273 Plant Material

274 Populus tremula $x$ alba line 717-1B4 and miR156 overexpressor line 40 described in 275 Lawrence et al., (2021) were obtained by in vitro propagation and hardened on propagation 276 media as described in Meilan \& Ma (2006). Plants were then transplanted to Fafard-2 growing 277 mix (Sun Gro Horticulture, Massachusetts, USA) in 0.3-L pots in the greenhouse at the 
278 University of Pennsylvania $\left(39.9493^{\circ} \mathrm{N}, 75.1995^{\circ} \mathrm{W}, 22.38 \mathrm{~m}\right.$ a.s.l.) and kept in plastic bags for 279 increased humidity for 2 weeks. Plants were transferred to 4.2-L pots with Fafard-52 growing 280 mix 3 weeks later and fertilized with Osmocote 14-14-14 (The Scotts Company, Marysville, OH, 281 USA). Plants were additionally fertilized once a week with Peters 20-10-20 (ICL Fertilizers, 282 Dublin, OH, USA). Greenhouse conditions consisted of a 16-hr photoperiod with temperatures 283 between 22 and $27^{\circ} \mathrm{C}$. Light levels were based on natural light and supplemented with $400-\mathrm{W}$ 284 metal halide lamps (P.L. Light Systems, Ontario, Canada) with daily irradiances between 300 to $2851,500 \mu \mathrm{mol} \mathrm{m}^{-2} \mathrm{~s}^{-1}$ across the day. All settings controlled by Priva (Ontario, Canada) and 286 Microgrow (Temecula, Canada) greenhouse systems.

287 Z. mays seeds with the Corngrass 1 (CgI) mutation (stock 310D)—which consists of a 288 tandem duplication of miR156b/c primary sequences described in Chuck et al. (2007) - and the 289 W22 inbred line were obtained from the Maize Genetics Cooperation Stock Center (Urbana, IL, 290 USA). Plants heterozygous for $C g l$ were crossed to W22 to produce the $C g l /+$ and $+/+$ siblings 291 used in this study. Seeds were planted in 9.09-L pots with Fafard-52 growing mix and fertilized 292 with Osmocote 14-14-14 in the greenhouse under growing conditions described above. A. thaliana $(\mathrm{Col})$ and the 35S:miR156 overexpressor line described in Wu \& Poethig 294 (2006) were planted in 0.06-L pots with Fafard-2 growing mix. Beneficial nematodes 295 (Steinernema feltiae, BioLogic, Willow Hill, PA), Marathon $\rightarrow 1 \%$ granular insecticide and 296 diatomaceous earth were added to the growing mix to control insects. Planted seeds were placed 297 at $4{ }^{\circ} \mathrm{C}$ for 3 days before being grown at $22^{\circ} \mathrm{C}$ in Conviron growth chambers (Pembina, ND, 298 USA) under short days ( $10 \mathrm{hrs}$. light $/ 14 \mathrm{hrs}$. dark) at $60 \mu \mathrm{mol} \mathrm{m}^{-2} \mathrm{~s}^{-1}$ light to obtain leaves large 299 enough to fit in the gas exchange chamber. Plants were fertilized with Peters 20-10-20 every 300 other week.

301 Individuals from genotypes of all species were positioned in a randomized fashion and 302 rotated frequently. Planting was staggered across two, three and five months for Arabidopsis, $P$. 303 tremula $x$ alba and Z. mays respectively.

Leaf samples

All samples were taken from the uppermost fully expanded leaf. For all three species, naturally juvenile and adult leaves in wild-type lines and "juvenilized" leaves, those in miR156 overexpressor lines with a juvenile phenotype at leaf positions that would normally be adult, 
were sampled. In P. tremula x alba, developmental stage was determined by petiole shape and

310 abaxial trichome density as described in Lawrence et al., (2021). Juvenile leaves were sampled

311 from wild-type node 10 and adult from node 25 , and juvenilized leaves were sampled from

312 overexpressor node 25. In Z. mays, developmental stage was determined by the presence or

313 absence of epicuticular wax and trichomes as described in Poethig (1988). Juvenile leaves were

314 sampled from node 4 and adult from node 11 in wildtype plants, and juvenilized leaves sampled

315 from node 4 in $C g 1$ mutants. In A. thaliana, developmental stage was determined by the presence

316 or absence of abaxial trichomes. Juvenile leaves were sampled from node 5 for physiological and

317 morphological measurements and nodes 2-5 for construction cost measures, and adult and

318 juvenilized from node 10 and 10-15 in wildtype and miR156 overexpressors, respectively.

Leaf Construction Cost Determination

Area of fresh leaf samples was determined from photographs using FIJI software

322 (Schindelin et al., 2012). Samples were then dried at $60^{\circ} \mathrm{C}$ until consistent mass, ground using a

323 Willey Mill until small enough to pass through a $2 \mathrm{~mm}$ grinding mesh, and then ground further

324 using a mortar and pestle. Each Z. mays sample consisted of $\sim 100 \mathrm{mg}$ tissue from one leaf, $P$.

325 tremula $x$ alba samples consisted of $\sim 100-120 \mathrm{mg}$ tissue from between 1 and 4 leaves, and $A$.

326 thaliana samples consisted of $\sim 60-80 \mathrm{mg}$ tissue from around 60 leaves. Chemical composition

327 analysis was performed as described in Cataldo et al., (1975), Poorter, (1994), and Poorter \&

328 Villar, (1997).

$3291 \mathrm{mg}$ from each sample was used to determine $\mathrm{C}$ and $\mathrm{N}$ using an ECS 4010 CHNSO

330 Analyzer (Costech Analytical Technologies INC, Valencia, CA, USA).

331 For nitrate determination, $20 \mathrm{mg}$ of sample was added to $2 \mathrm{ml} 80^{\circ} \mathrm{C}$ water for 20 mins for

332 nitrate extraction. Samples were centrifuged at $5000 \mathrm{rcf}$ for $15 \mathrm{mins} .0 .2 \mathrm{ml}$ of supernatant was

333 mixed with $0.8 \mathrm{ml}$ of $5 \%$ (w/v) salicylic acid in $\mathrm{H}_{2} \mathrm{SO}_{4}$ and incubated at room temperature for 20

334 mins. Following incubation, $19 \mathrm{ml}$ of $2 \mathrm{~N} \mathrm{NaOH}$ was added to samples. Absorbance of $410 \mathrm{~nm}$

335 was determined for $0.2 \mathrm{ml}$ aliquots of each sample and $\mathrm{NO}^{-}{ }_{3}-\mathrm{N}$ standards of 1 to $200 \mu \mathrm{g}$, used to

336 create a standard curve.

337 The remaining tissue was weighed and used for mineral determination. Samples were

338 ashed at $550^{\circ} \mathrm{C}$ in a muffle furnace for $6 \mathrm{hrs}$ and weighed again. Ash alkalinity was determined

339 in duplicate for each sample to measure $\mathrm{CO}_{3}{ }^{-2}$ that formed when oxides from the plant tissue 
reacted with $\mathrm{CO}_{2}$ upon cooling. $4 \mathrm{mg}$ of ash was mixed in $5 \mathrm{~mL}$ of deionized $\mathrm{H}_{2} \mathrm{O}$ and 2-3 drops of $0.5 \%$ phenolphthalein were added. The solution was titrated with $0.5 \mathrm{~N} \mathrm{HCl}$ until the pink

342 indicator color disappeared. An additional volume of $\mathrm{HCl}$, equal to that needed for titration plus 343 an additional $2 \mathrm{~mL}$, was added to the sample. The solution was then boiled for 5 mins, cooled to room temperature and an additional 2-3 drops of phenolphthalein were added. Samples were then back titrated with $0.5 \mathrm{~N} \mathrm{NaOH}$ until a faint pink color persisted. The average alkalinity from the two replicates of each sample was used in calculations.

All equations for calculations are presented in the appendix. Ash alkalinity was calculated using equation (1.1), mineral content equation (1.2), and construction cost of leaf

349 tissue in grams of glucose using equation (1.3). Tissue mass lost in this process was assumed to 350 have the same chemical composition as that recovered.

\section{Photosynthetic Measurements}

All gas exchange measurements were made using a Li-6400 portable photosynthesis machine (Li-Cor Environmental, Lincoln, NE, USA) at a leaf temperature of $25^{\circ} \mathrm{C}$ following acclimatization to starting chamber conditions. Light response curves were performed in all three species at a reference $\left[\mathrm{CO}_{2}\right]$ of $400 \mathrm{ppm}$ using a minimum wait time of 2 mins between light level changes and data logging. Net photosynthetic rate $\left(\mathrm{A}_{\mathrm{net}}\right)$ in A. thaliana was measured at light levels of 1000, 800,600,300, 200, 150, 100, 75, 50, 25, $0 \mu \mathrm{mol} \mathrm{m}^{-2} \mathrm{~s}^{-1}$ at a flow rate of 300 $\mu \mathrm{mol}$ air sec $\mathrm{s}^{-1}$ in Zea mays at light levels of 1800, 1500, 1200, 1000, 800, 600, 300, 200, 150, $100,75,50,25,0 \mu \mathrm{mol} \mathrm{m} \mathrm{m}^{-2} \mathrm{~s}^{-1}$ at a flow rate of $400 \mu \mathrm{mol}$ air $\mathrm{sec}^{-1}$, and $P$. tremula $x$ alba at light levels of 1500, 1200, 1000, 800,600,300, 200, 150, 100, 75, 50, 25, 10 and $0 \mu \mathrm{mol} \mathrm{m} \mathrm{m}^{-2} \mathrm{~s}^{-1}$ a

362 flow rate of $400 \mu \mathrm{mol}$ air $\mathrm{sec}^{-1}$.Light response curves were analyzed using the (AQ Curve 363 fitting\} script in R (Tomeo, 2019) which uses equations based on a standard non-rectangular 364 hyperbola model fit described in Lobo et al. (2013) and found in the appendix as equation (2.1).

Photosynthetic induction was measured on leaves exposed to light levels less than 20 $366 \mu \mathrm{mol} \mathrm{m} \mathrm{m}^{-2}$ for a minimum of 20 mins. Induction was measured by logging every 10 seconds as

367 leaves were exposed to $20 \mu \mathrm{mol} \mathrm{m}^{-2} \mathrm{~s}^{-1}$ of light for $2 \mathrm{mins}$ and then shifted to saturating light, $3681800 \mu \mathrm{mol} \mathrm{m}{ }^{-2} \mathrm{~s}^{-1}$ for P. tremula $x$ alba and Z. mays or $1000 \mu \mathrm{mol} \mathrm{m}^{-2} \mathrm{~s}^{-1}$ for A. thaliana, for 20 369 mins. 
All equations for calculations are described in Poorter, (1994) and Poorter et al., (2006)

373 and presented in the appendix. Assimilation and respiration rates were converted from $\mu \mathrm{mol} \mathrm{CO}_{2}$

$374 \mathrm{~m}^{-2}$ to grams of glucose per gram of tissue using equation (3.1). Specific leaf area (SLA) used in

375 this equation was calculated by dividing the fresh leaf area by its dry weight. Payback time, the

376 time in days required for leaves to assimilate the equivalent glucose needed to construct it, was

377 determined using equation (4.1). Return on investment (ROI) was calculated using equation

378 (4.2). Leaf lifespan represents the photosynthetic lifespan measured as the time between full

379 expansion and senescence, determined by the first signs of discoloration. Payback time and ROI

380 calculations were based on days with $12 \mathrm{hr}$ day/night cycles. Assimilation was modeled using

381 equation (2.1) with the light response curve parameters previously determined. Respiration $\left(\mathrm{R}_{\mathrm{d}}\right)$

382 used in these equations was estimated as $7 \% \mathrm{~A}_{\text {sat }}$ to minimize measurement errors that may arise

383 when measuring low gas exchange rates with portable photosynthesis machines as suggested in

384 Poorter et al., (2006). For calculations of payback time and ROI in constant light environments,

385 integrated daily photon flux density (PPFD) was calculated using equation (5.1).

386

\section{Dynamic Light Environment Model}

All parts of the dynamic light environment model were written in R (R Core Team, 2018) and provided as RMarkdown files in the supplement of this manuscript. All equations used are provided in the appendix.

$391 \quad$ Part 1 of the model determines light levels across the day based on Campbell \& Norman, 392 (1998), Zhu et al., (2004) and Salter et al., (2019). Solar declination angle (eq. 6.1), hour angle 393 (eq. 6.2), and solar elevation angle (eq. 6.3) were calculated using a latitude of Philadelphia, PA, 394 USA $\left(39.95^{\circ} \mathrm{N}\right.$ or $\left.0.697 \mathrm{rads}\right)$ and Julian day of 180 . Direct and diffuse light were calculated 395 using equations (6.4) and (6.5) respectively. Solar constant was assumed to be $2600 \mu \mathrm{mol} \mathrm{m}^{-2} \mathrm{~s}^{-1}$ 396 and atmospheric transmissivity 0.75. Light levels during sun and shade flecks were determined 397 using equations (6.6) and (6.7) respectively. Leaf area index (LAI) varied between 0.5 and 8 for 398 each simulation and are reported in Table S5.

Part 2 of the model determines when light switches between sun and shadeflecks using 400 equations (7.1) and (7.2) described in Salter et al., (2019). Day light began at 6:00 and ended at 
401 18:00 with simulations set to begin with a sunfleck. Initial sunfleck lengths varied between 402 simulations and are reported Table S5.

403 Part 3 of the model determines assimilation across the day using variables from the light 404 response curves and photosynthetic induction measurements based on Woodrow \& Mott, (1989), 405 Mott \& Woodrow, (2000), and Taylor \& Long, (2017). To determine tau, which describes 406 Rubisco kinetics for photosynthetic induction, $A_{\text {sat }}$ and instantaneous net photosynthetic rate $407\left(\mathrm{~A}_{\text {net }}\right)$ during induction were corrected for changes in intercellular $\left[\mathrm{CO}_{2}\right]\left(\mathrm{C}_{\mathrm{i}}\right)$ using equations 408 (8.1) and (8.2) respectively. $\mathrm{C}_{\mathrm{i}}$ corrected measures of $\mathrm{A}_{\text {sat }}$ are referred to as $\mathrm{A}_{\mathrm{f}}{ }^{*}$ and $\mathrm{A}_{\text {net }}$ as $\mathrm{A}^{*}$. 409 Tau during increases in light was then calculated as the inverse of the linear slope of $\ln \left(\mathrm{A}_{\mathrm{f}}^{*}-\mathrm{A}^{*}\right)$ 410 vs Time for minutes 1-10 of induction upon exposure to high-light (eq. 8.3). The initial minute of 411 induction, often referred to as the 'fast phase', was excluded from our model because 1) 412 increases in $\mathrm{A}_{\text {net }}$ during this phase are primarily governed by increases in the pool of $\mathrm{RuBP}$ and 413 therefore, Rubsico kinetics cannot accurately be estimated using gas exchange, and 2) at times 414 greater than $1 \mathrm{~min}$, which is the resolution of our model, the contribution of this phase to $\mathrm{A}_{\text {net }}$ is 415 negligible and can be excluded (Woodrow \& Mott, 1989). At times greater than 10 mins, most 416 changes in $\mathrm{A}_{\text {net }}$ are governed by stomatal opening, and therefore $\mathrm{A}^{*}$ shows little change 417 (Woodrow \& Mott, 1989). Tau during decreases in light describes the deactivation of Rubisco. 418 Because $\mathrm{A}_{\text {net }}$ decreases more quickly than Rubisco deactivation when light levels are reduced, 419 tau during deactivation is difficult to estimate using gas exchange. Woodrow \& Mott, (1989) 420 showed that when measured biochemically, tau during deactivation was roughly $5 \mathrm{x}$ tau during 421 induction, we therefore estimated our values in this way. Induction state, representing the percent 422 of $\mathrm{A}_{\text {sat }}$ instantaneous assimilation is at during induction was calculated by equation (8.4). $423 \quad A_{n e t}$ throughout the day required the calculation of the potential maximum assimilation 424 rate $\left(A_{f}\right.$, eq. 9.1) and initial assimilation rate prior to induction $\left(A_{i}\right.$, eq. 9.2) for each 1 min 425 interval as described in Woodrow \& Mott, (1989) and Taylor \& Long, (2017). Tau, $A_{f}$ and $A_{i}$ 426 were then used in equation (9.3), as described in Mott \& Woodrow, (2000), to calculate $A_{\text {net }}$ for 427 each time point. Integrated assimilation $\left(\mathrm{A}_{\mathrm{int}}\right)$ across each modeled $1 \mathrm{~min}$ interval was calculated 428 by equation (9.4). To estimate the loss in assimilation due to lags in the response of 429 photosynthesis to light, $A_{\text {int }}$ with a square response to each change in light was calculated by 430 setting tau equal to 0 in equation (9.4). Subtracting $A_{\text {int }}$ with induction responses (tau $=$ slope of 
$431 \ln \left(\mathrm{A}_{\mathrm{f}}^{*}-\mathrm{A}^{*}\right)$ vs Time $)$ from $\mathrm{A}_{\text {int }}$ with immediate square responses to light $(\operatorname{tau}=0)$ provides the 432 loss in assimilation due to Rubisco activation.

433 Part 4 of the model uses the same equations described above to calculate payback time 434 and ROI for each simulation. For all modeled calculations, median values for each species and 435 developmental stage were used for assimilation variables and mean values for construction cost 436 and leaf trait variables.

Statistical Analysis

All statistical analyses were performed in JMP ${ }^{\circledR}$ Pro v. 14.0.0 (SAS Institute Inc., Cary, NC). Leaf composition, leaf morphology, construction cost, and light response curve parameters between adult, juvenile and juvenilized leaves of each species were compared by one-way ANOVA, where developmental stage was the main effect. When ANOVA results were significant $(p<0.05)$, a Student's $t$ test was performed to determine differences between developmental groups. Traits were considered to be affected by developmental phase when adult leaves were significantly different from both juvenile and juvenilized leaves with the same trend. Light induction parameters and leaf lifespan of juvenile and adult leaves of each species were compared using a Student's $t$ test and considered significantly different when $p<0.05$. Payback time, ROI, photosynthetic rate during induction, induction state, and lost assimilation due to slow induction for each species were compared by ANCOVA with developmental stage as the covariate and considered significantly different when $p<0.05$.

\section{Acknowledgements}

We thank Samara Gray and Joshua Darfler for their assistance in caring for the plants used in this study. This research was funded by the NSF Graduate Research Fellowship (Division of Graduate Education; DGE-1845298), U. of Pennsylvania SAS Dissertation Research Fellowship and the Peachey Research Fund awarded to E.H.L. and NIH GM51893 awarded to R.S.P. 
462 Michaletz ST, et al. 2020. The leaf economics spectrum constrains phenotypic plasticity across 463 a light gradient. Frontiers in Plant Science 11: 735.

464 Anderegg LDL, Berner LT, Badgley G, Sethi ML, Law BE, HilleRisLambers J. 2018.

465 Within-species patterns challenge our understanding of the leaf economics spectrum. Ecology 466 Letters 21: 734-744.

467 Axtell MJ, Bowman JL. 2008. Evolution of plant microRNAs and their targets. Trends in Plant 468 Science 13: 343-349.

469 Campbell GS, Norman JM. 1998. An Introduction to Environmental Biophysics. New York:

470 Springer Verlag.

471 Cataldo DA, Haroon MH, Schrader LE, Youngs VL. 1975. Rapid colorimetric determination 472 of nitrate in plant tissue by nitration of salicylic acid. Communications in Soil Science and Plant 473 Analysis 6: 71-80.

474 Chazdon RL, Pearcy RW. 1991. The Importance of Sunflecks for Forest Understory Plants. 475 BioScience 41: 760-766.

476 Chuck G, Cigan M, Saeteurn K, Hake S. 2007. The heterochronic maize mutant Corngrass 1 477 results from overexpression of a tandem microRNA. Nature genetics 39: 544-549.

478 Coley PD. 1988. Effects of plant growth rate and leaf lifetime on the amount and type of anti479 herbivore defense. Oecologia 74: 531-536.

480 Damián X, Fornoni J, Domínguez CA, Boege K. 2018. Ontogenetic changes in the phenotypic 481 integration and modularity of leaf functional traits. Functional Ecology 32: 234-246.

482 Edwards EJ, Chatelet DS, Sack L, Donoghue MJ. 2014. Leaf life span and the leaf economic 483 spectrum in the context of whole plant architecture (W Cornwell, Ed.). Journal of Ecology 102: $484 \quad 328-336$.

485 Feng S, Xu Y, Guo C, Zheng J, Zhou B, Zhang Y, Ding Y, Zhang L, Zhu Z, Wang H, et al. 486 2016. Modulation of miR 156 to identify traits associated with vegetative phase change in 487 tobacco (Nicotiana tabacum). Journal of Experimental Botany 67: 1493-1504.

488 Funk JL, Larson JE, Vose G. 2020. Leaf traits and performance vary with plant age and water 489 availability in Artemisia californica. Annals of Botany 3: 1-9.

490 Hayes FJ, Buchanan SW, Coleman B, Gordon AM, Reich PB, Thevathasan N V, Wright 491 IJ, Martin AR. 2019. Intraspecific variation in soy across the leaf economics spectrum. Annals 492 of Botany 123: 107-120. 
493 Hikosaka K. 2004. Interspecific difference in the photosynthesis-nitrogen relationship: Patterns,

494 physiological causes, and ecological importance. Journal of Plant Research 117: 481-494.

495 Lawrence EH, Leichty AR, Doody EE, Ma C, Strauss SH, Poethig RS. 2021. Vegetative

496 phase change in Populus tremula x alba. New Phytologist: nph.17316.

497 Lawrence EH, Springer CJ, Helliker BR, Poethig RS. 2020. MicroRNA156-mediated

498 changes in leaf composition lead to altered photosynthetic traits during vegetative phase change.

499 New Phytologist: nph.17007.

500 Liu Z, Jiang F, Li F, Jin G. 2019. Coordination of intra and inter-species leaf traits according to

501 leaf phenology and plant age for three temperate broadleaf species with different shade

502 tolerances. Forest Ecology and Management 434: 63-75.

503 Lobo F de A, de Barros MP, Dalmagro HJ, Dalmolin ÂC, Pereira WE, de Souza ÉC,

504 Vourlitis GL, Rodríguez Ortíz CE. 2013. Fitting net photosynthetic light-response curves with

505 Microsoft Excel - a critical look at the models. Photosynthetica 51: 445-456.

506 Mason CM, Donovan LA. 2015a. Does investment in leaf defenses drive changes in leaf

507 economic strategy? A focus on whole-plant ontogeny. Oecologia 177: 1053-1066.

508 Mason CM, Donovan LA. 2015b. Evolution of the leaf economics spectrum in herbs: Evidence

509 from environmental divergences in leaf physiology across Helianthus (Asteraceae). Evolution

510 69: 2705-2720.

511 Mason CM, Mcgaughey SE, Donovan LA. 2013. Ontogeny strongly and differentially alters

512 leaf economic and other key traits in three diverse Helianthus species. Journal of Experimental

513 Botany 64: 4089-4099.

514 Meilan R, Ma C. 2006. Poplar (Populus spp.). In: Wang K, ed. Methods in Molecular Biology:

515 Agrobacterium Protocols. Totowa, NJ: Humana Press Inc., 143-151.

516 Mott KA, Woodrow IE. 2000. Modelling the role of Rubisco activase in limiting non-steady-

517 state photosynthesis. Journal of Experimental Botany 51: 399-406.

518 Niinemets Ü. 2004. Adaptive adjustments to light in foliage and whole-plant characteristics

519 depend on relative age in the perennial herb Leontodon hispidus. New Phytologist 162: 683-696.

520 Poethig RS. 1988. Heterochronic mutations affecting shoot development in maize. Genetics 119: 521 959-73.

522 Poorter H. 1994. Construction costs and payback time of biomass: A whole plant perspective.

523 In: J. Roy and E. Garnier, ed. A Whole Plant Perspective on Carbon-Nitrogen Interactions. The 
524 Netherlands: SPB Academic Publishing, 111-127.

525 Poorter H, Niinemets Ü, Poorter L, Wright IJ, Villar R. 2009. Causes and consequences of

526 variation in leaf mass per area (LMA): a meta-analysis. New Phytologist 182: 565-588.

527 Poorter H, Pepin S, Rijkers T, De Jong Y, Evans JR, Kö Rner C. 2006. Construction costs,

528 chemical composition and payback time of high-and low-irradiance leaves. Journal of

529 Experimental Botany 57: 355-371.

530 Poorter H, Villar R. 1997. The Fate of Acquired Carbon in Plants: Chemical Composition and

531 Construction Costs. In: Bazzaz FA, Grace J, eds. Plant Resource Allocation. New York:

532 Academic Press, 39-72.

533 Reich PB. 2014. The world-wide 'fast-slow' plant economics spectrum: A traits manifesto.

534 Journal of Ecology 102: 275-301.

535 Reich PB, Ellsworth DS, Walters MB. 1998. Leaf structure (specific leaf area) modulates

536 photosynthesis-nitrogen relations: evidence from within and across species and functional

537 groups. Functional Ecology 12: 948-958.

538 Reich PB, Walters MB, Ellsworth DS. 1992. Leaf Life-Span in Relation to Leaf, Plant, and

539 Stand Characteristics among Diverse Ecosystems. Ecological Monographs 62: 365-392.

540 Russo SE, Kitajima K. 2016. The Ecophysiology of Leaf Lifespan in Tropical Forests:

541 Adaptive and Plastic Responses to Environmental Heterogeneity. In: Goldstein G, Santiago LS,

542 eds. Tropical Tree Physiology. Switzerland: Springer International Publishing, 357-383.

543 Salter WT, Merchant AM, Richards RA, Trethowan R, Buckley TN. 2019. Rate of

544 photosynthetic induction in fluctuating light varies widely among genotypes of wheat. Journal of

545 Experimental Botany 70: 2787-2796.

546 Schindelin J, Arganda-Carreras I, Frise E, Kaynig V, Longair M, Pietzsch T, Preibisch S,

547 Rueden C, Saalfeld S, Schmid B, et al. 2012. Fiji: An open-source platform for biological-

548 image analysis. Nature Methods 9: 676-682.

549 Taylor SH, Long SP. 2017. Slow induction of photosynthesis on shade to sun transitions in 550 wheat may cost at least $21 \%$ of productivity. Philosophical Transactions of the Royal Society B 551 372: 20160543.

552 Terashima I, Hanba YT, Tazoe Y, Vyas P, Yano S. 2006. Irradiance and phenotype:

553 Comparative eco-development of sun and shade leaves in relation to photosynthetic CO2

554 diffusion. Journal of Experimental Botany 57: 343-354. 
555 Terashima I, Hikosaka K. 1995. Comparative ecophysiology of leaf and canopy

556 photosynthesis. Plant, Cell \& Environment 18: 1111-1128.

557 Tomeo N. 2019. Tomeopaste/AQ_curves: AQ_curve fitting release 1.

558 doi.org/10.5281/zenodo.3497557.

559 Wang JW, Schwab R, Czech B, Mica E, Weigel D. 2008. Dual effects of miR156-targeted

560 SPL genes and CYP78A5/KLUH on plastochron length and organ size in Arabidopsis thaliana.

561 Plant Cell 20: 1231-1243.

562 Woodrow IE, Mott KA. 1989. Rate limitation of non-steady-state photosynthesis by ribulose-

563 1,5-bisphosphate carboxylase in spinach. Australian Journal of Plant Physiology 16: 487-500.

564 Wright IJ, Reich PB, Westoby M, Ackerly DD, Baruch Z, Bongers F, Cavender-Bares J,

565 Chapin T, Cornelissen JHC, Diemer M, et al. 2004. The worldwide leaf economics spectrum.

566 Nature 428: 821-827.

567 Wu G, Poethig RS. 2006. Temporal regulation of shoot development in Arabidopsis thaliana by

568 miR156 and its target SPL3. Development 133: 3539-3547.

569 Zhu X-G, Ort DR, Whitmarsh J, Long SP. 2004. The slow reversibility of photosystem II

570 thermal energy dissipation on transfer from high to low light may cause large losses in carbon

571 gain by crop canopies: a theoretical analysis. Journal of Experimental Botany 55: 1167-1175.

572

573 
575 Table 1. Leaf composition of adult, juvenile and juvenilized leaves of $P$. tremula $x$ alba, $A$

576 thaliana and Z. mays. Values indicate the mean \pm standard error. For traits where ANOVA

577 results were significant $(p<0.05)$, lower case letters indicate significant $(p<0.05)$ differences

578 between developmental groups determined by a Student's $t$ test.

\begin{tabular}{ccccccc} 
Species & $\begin{array}{c}\text { Developmen } \\
\mathbf{t}\end{array}$ & $\begin{array}{c}\text { Carbon } \\
\left(\mathbf{m g ~ g}^{-1}\right)\end{array}$ & $\begin{array}{c}\text { Nitrogen } \\
\left(\mathbf{m g ~ g}^{-1}\right)\end{array}$ & $\begin{array}{c}\text { Nitrate } \\
\left(\mathbf{m g ~ g}^{-1}\right)\end{array}$ & $\begin{array}{c}\text { Mineral } \\
\left(\mathbf{m g ~ g}^{-1}\right)\end{array}$ & $\mathbf{n}$ \\
\hline P. tremula $x$ alba & Adult & $793.96 \pm 29.96$ & $37.06 \pm 2.24$ & $0.14 \pm 0.03^{\mathrm{b}}$ & $168.97 \pm 30.86^{\mathrm{b}}$ & 5 \\
& Juvenile & $730.22 \pm 69.20$ & $63.22 \pm 11.25$ & $0.31 \pm 0.10^{\mathrm{a}}$ & $206.56 \pm 59.56^{\mathrm{b}}$ & 4 \\
& Juvenilized & $618.49 \pm 72.95$ & $72.92 \pm 17.19$ & $0.21 \pm 0.04^{\mathrm{b}}$ & $308.58 \pm 59.60^{\mathrm{a}}$ & 5 \\
& & & & & & \\
\hline \multirow{2}{*}{ A. thaliana } & Adult & $547.87 \pm 72.32$ & $106.03 \pm 28.01$ & $2.10 \pm 0.39^{\mathrm{b}}$ & $346.1 \pm 69.95$ & 3 \\
& Juvenile & $564.59 \pm 10.70$ & $98.11 \pm 27.55$ & $2.58 \pm 0.24^{\mathrm{a}}$ & $337.29 \pm 37.08$ & 3 \\
& Juvenilized & $536.19 \pm 22.86$ & $123.82 \pm 7.97$ & $2.46 \pm 0.21^{\mathrm{a}}$ & $339.98 \pm 30.77$ & 3 \\
\hline \multirow{3}{*}{ Z. mays } & & & & & & \\
& Adult & $772.74 \pm 5.21^{\mathrm{a}}$ & $24.73 \pm 3.43^{\mathrm{b}}$ & $0.09 \pm 0.01^{\mathrm{b}}$ & $202.52 \pm 3.26^{\mathrm{c}}$ & 5 \\
& Juvenile & $620.09 \pm 5.69^{\mathrm{b}}$ & $42.86 \pm 4.82^{\mathrm{a}}$ & $0.30 \pm 0.04^{\mathrm{a}}$ & $337.05 \pm 8.44^{\mathrm{a}}$ & 5 \\
& Juvenilized & $687.2 \pm 14.14^{\mathrm{c}}$ & $43.77 \pm 1.33^{\mathrm{a}}$ & $0.17 \pm 0.02^{\mathrm{b}}$ & $269.03 \pm 14.00^{\mathrm{b}}$ & 5 \\
\hline
\end{tabular}



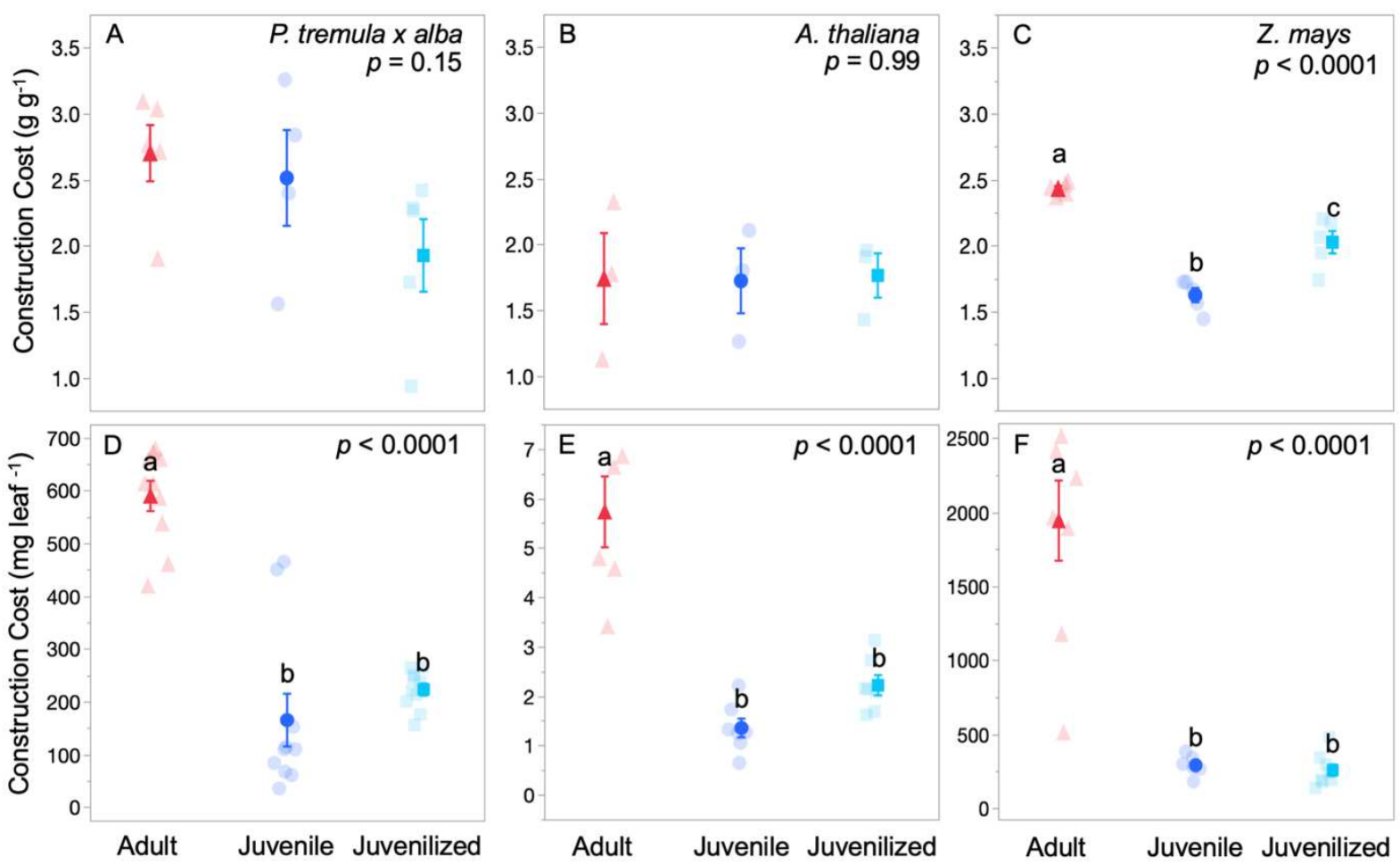

581

582

583

584

585

586

587

588

589

Figure 1. Construction cost in grams of glucose per gram of leaf tissue (A-C) or per leaf (D-F) for adult (red triangles), Juvenile (blue circles), and juvenilized (light blue squares) leaves of $P$. tremula $x$ alba (A, D), A. thaliana (B, E), and Z. mays (C-F). Data presented as means \pm s.e.m. by solid symbols and individual replicates by transparent symbols. $P$-values determined by oneway $A N O V A$ with leaf development as the effect. Different lower-case letters represent groups significantly different from each other as determined by Student's $T$. 

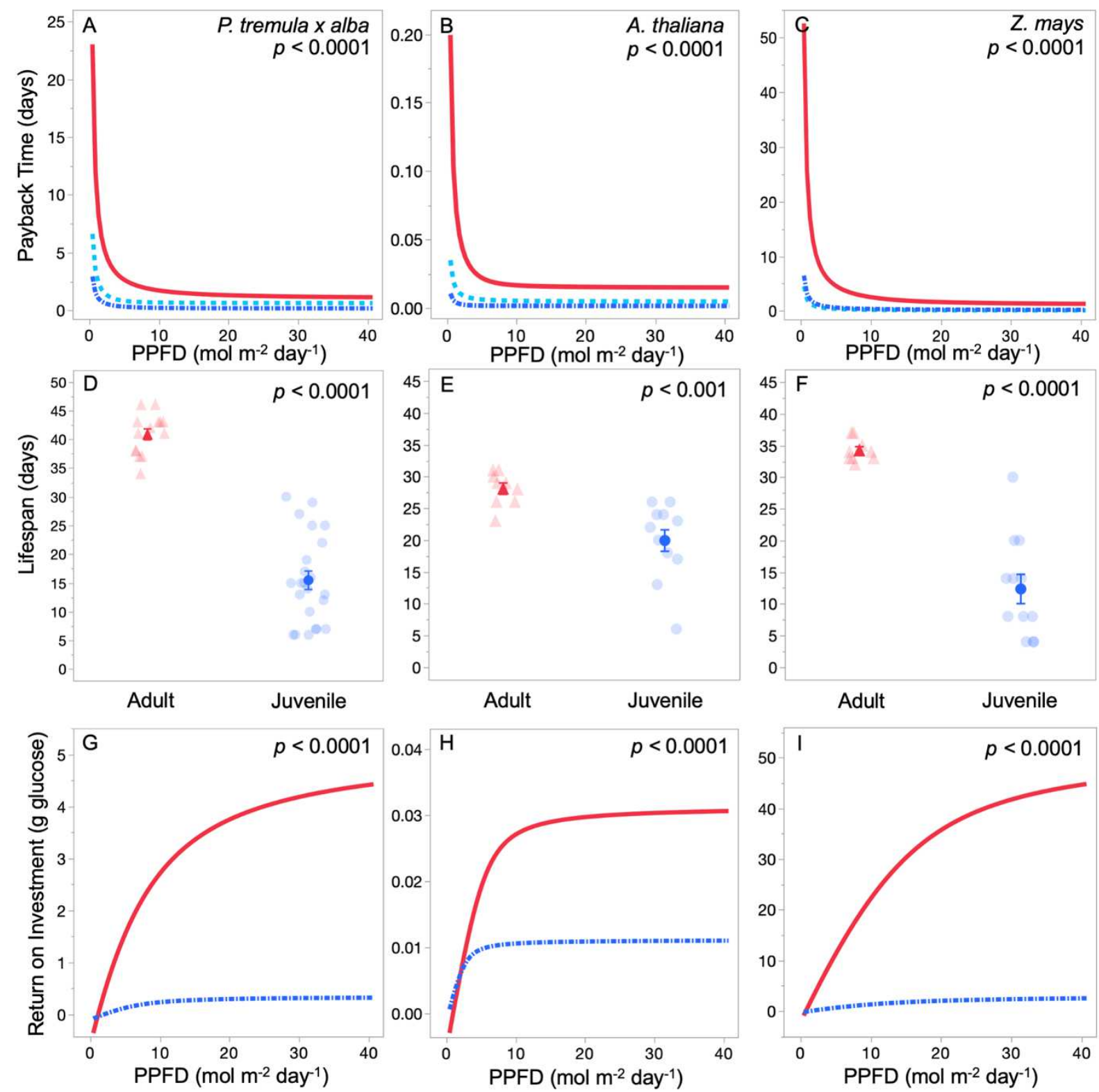

-Adult "- Juvenile "- Juvenilized

Figure 2. Payback time per leaf (A-C), leaf lifespan (D-F) and return on investment (ROI) per leaf in grams of glucose (G-I) for adult (red triangles and solid lines), juvenile (blue circles and dash-dotted lines), and juvenilized (light blue squares and dashed lines) leaves of $P$. tremula $x$ alba (A, D, G), A. thaliana (B, E, H), and Z. mays (C, F, I). Payback time and ROI are modeled using photosynthetic light response parameters and 12-hour light periods with constant PAR levels between 10 and $940 \mu \mathrm{mol} \mathrm{m} \mathrm{m}^{1}$ and are plotted against the resulting daily integrated photosynthetic photon flux density (PPFD). Leaf lifespan data presented as means \pm s.e.m. by solid symbols and individual replicates by transparent symbols. $P$-values determined by 

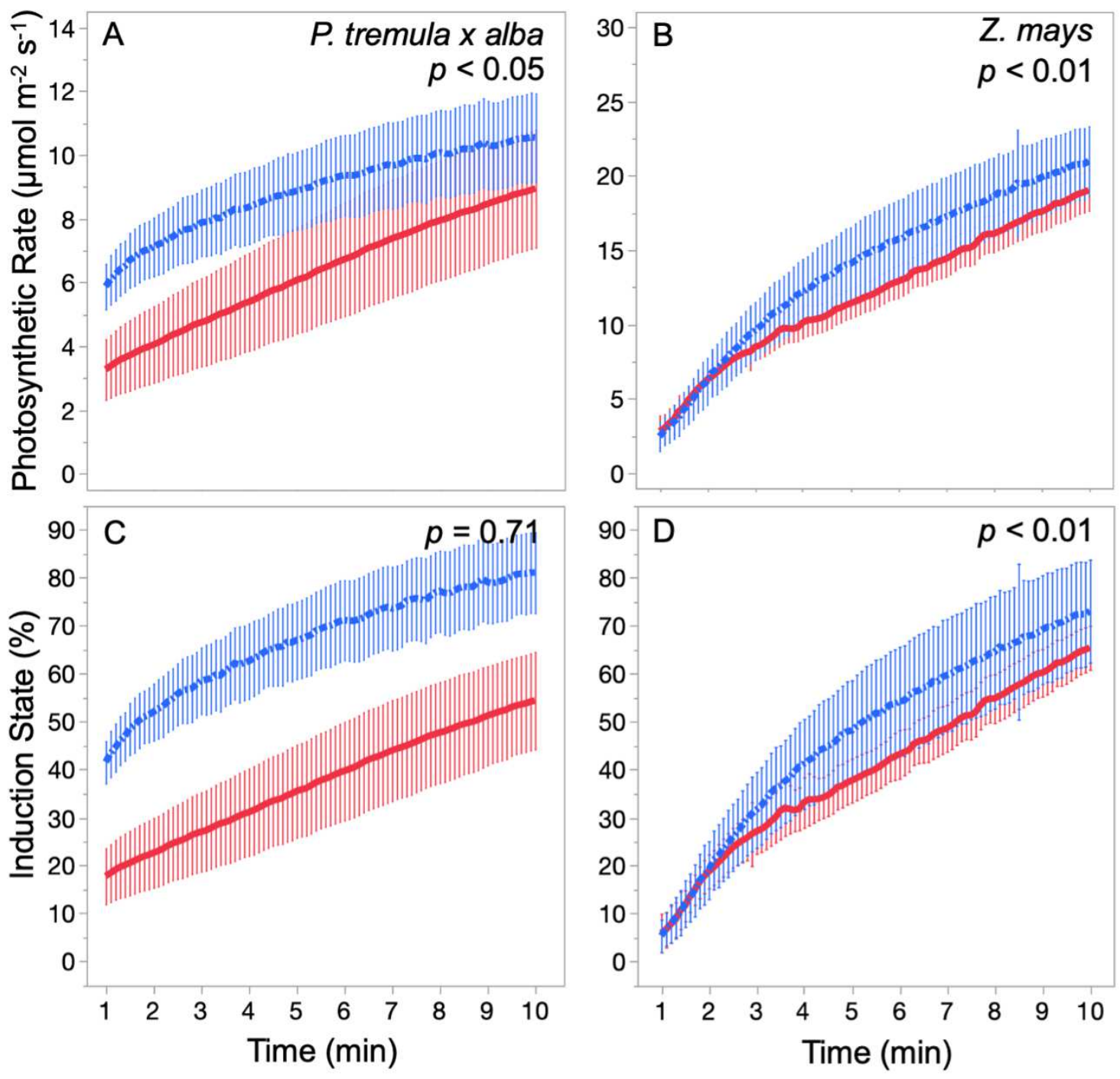

-Adult -" Juvenile

601

602

603

604

605

606
Figure 3. Photosynthetic rate and photosynthetic induction state during minutes 1-10 of exposure to saturating light for adult (solid, red) and juvenile (dash-dotted, blue) leaves of $P$. tremula $x$ alba $(\mathrm{A}, \mathrm{C})$ and $Z$. mays $(\mathrm{B}, \mathrm{D})$. Data presented as the mean \pm s.e.m. $P$-values determined by ANCOVA. 

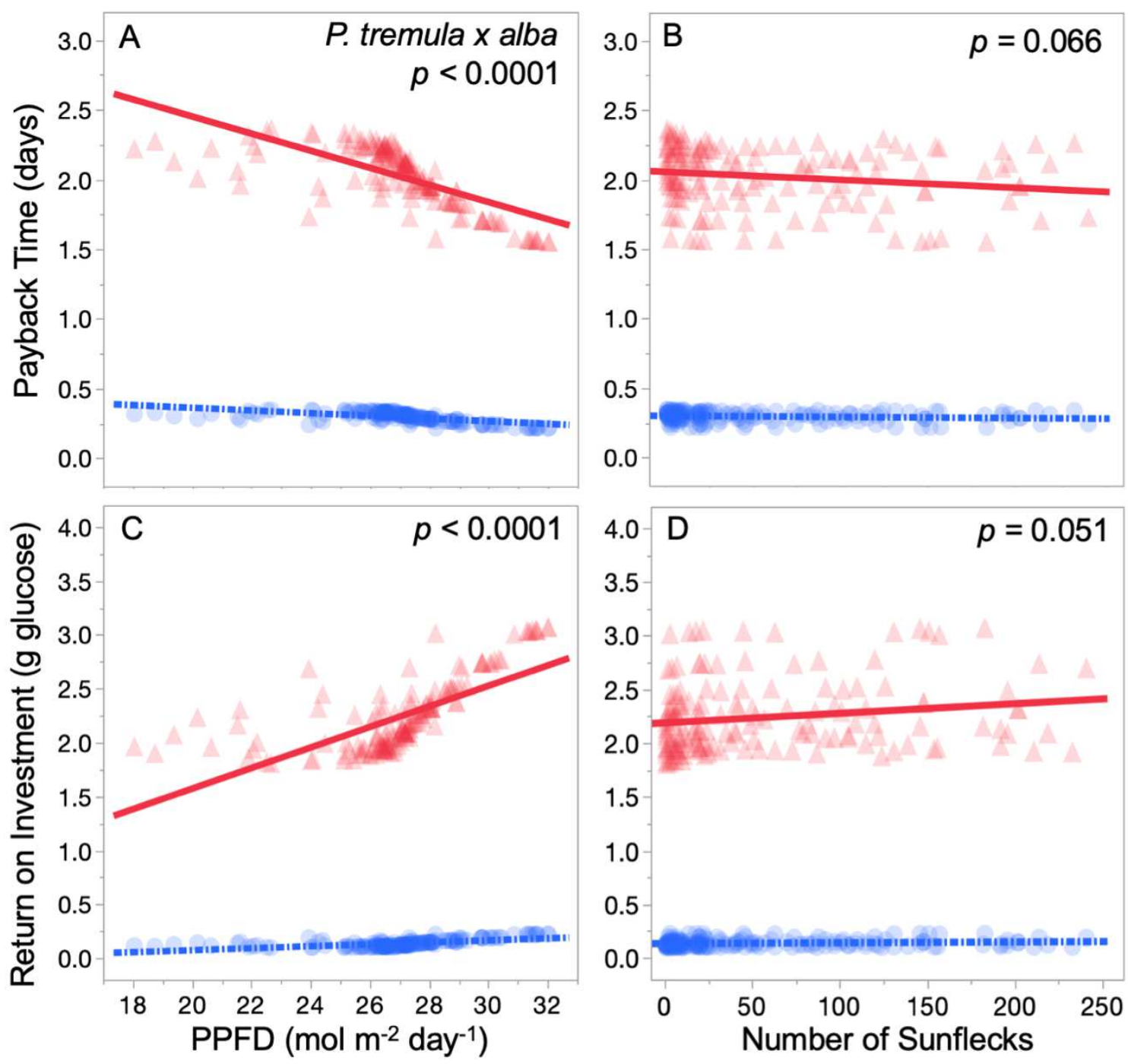

\section{-Adult -".suvenile}

607

608

609

610

611

612

613
Figure 4. Leaf payback time (A-B) and return on investment (C-D) for adult (red triangles and solid lines) and juvenile (blue circles and dash-dotted lines) leaves from simulated dynamic light environments in P. tremula $x$ alba plotted against daily integrated PPFD (A, C) and number of sunflecks across the day $(\mathrm{B}, \mathrm{D})$. Data presented as individual replicates by transparent symbols and linear line of best-fit. $P$-values determined by $A N C O V A$. 

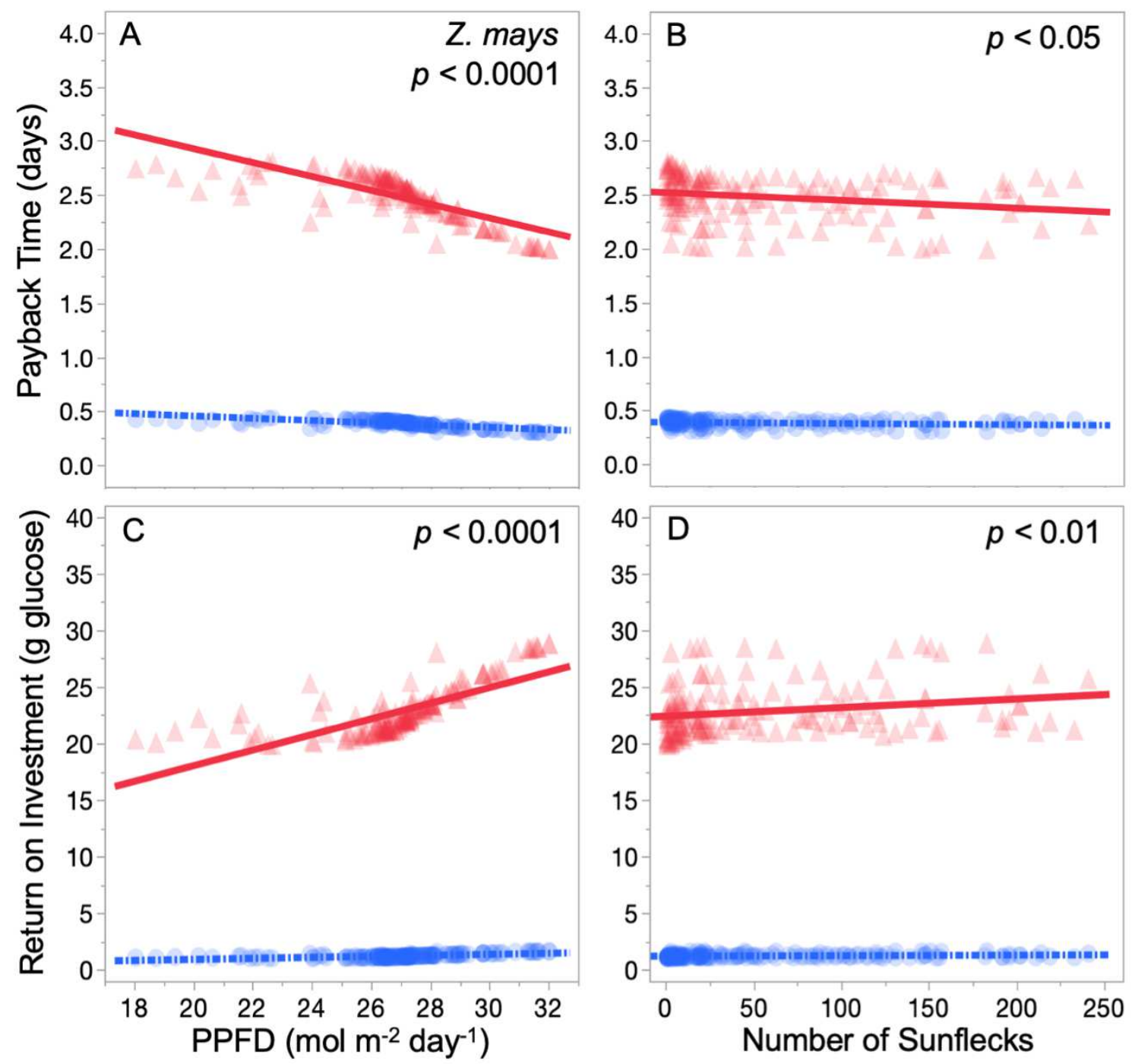

-Adult =- Juvenile

615

616

617

618

619

620

621
Figure 5. Leaf payback time (A-B) and return on investment (C-D) for adult (red triangles and solid lines) and juvenile (blue circles and dash-dotted lines) leaves from simulated dynamic light environments in Z. mays plotted against daily integrated PPFD (A, C) and number of sunflecks across the day $(B, D)$. Data presented as individual replicates by transparent symbols and linear line of best-fit. $P$-values determined by $A N C O V A$. 

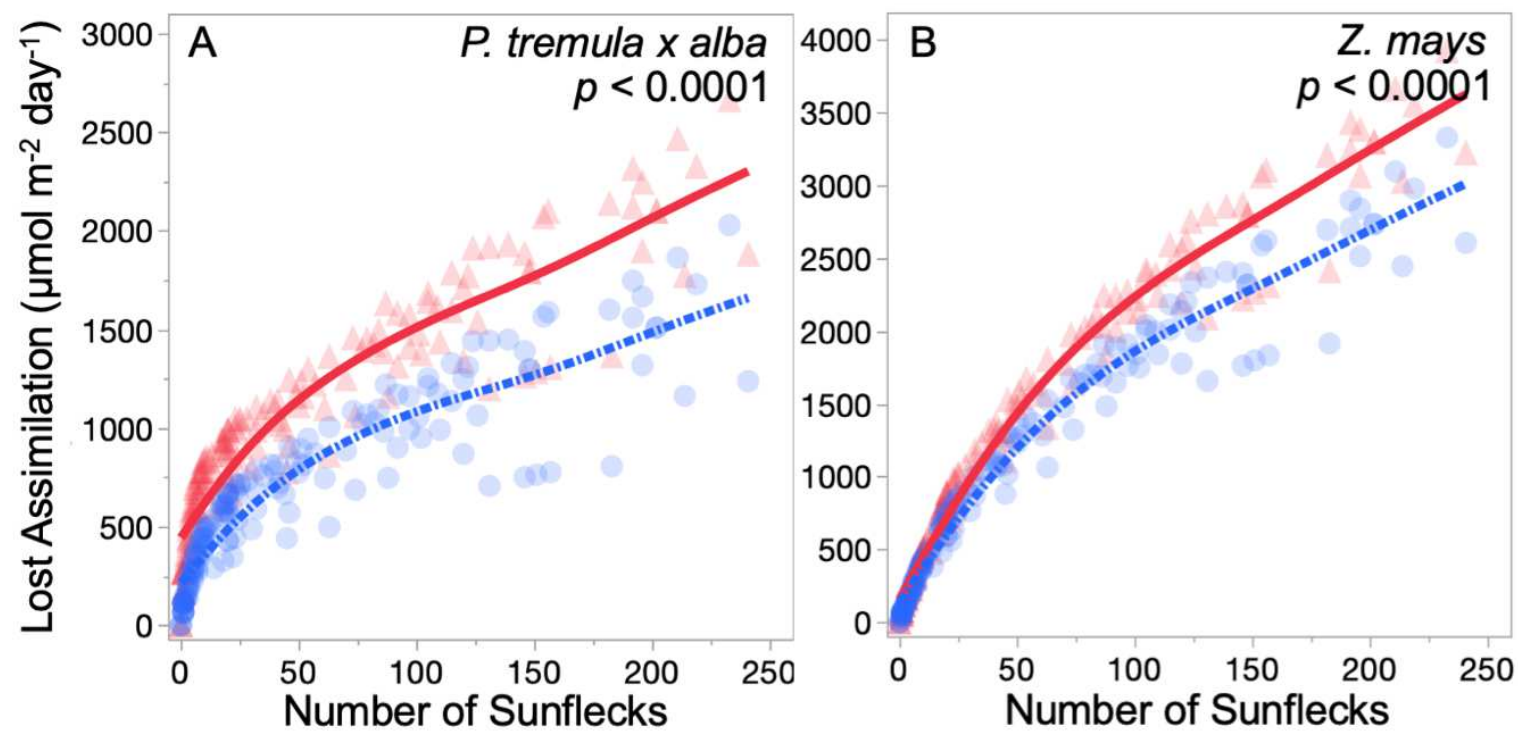

622 -Adult ="- Juvenile

Figure 6. Lost assimilation due to slow photosynthetic induction in simulated dynamic light environments for adult (red triangles and solid line) and juvenile (blue circles and dash-dotted line) in P. tremula x alba (A) or Z. mays (B) plotted against number of sunflecks across the day. 628 Data presented as individual replicates by transparent symbols and smoothed mean line. $P$-values determined by ANCOVA. 


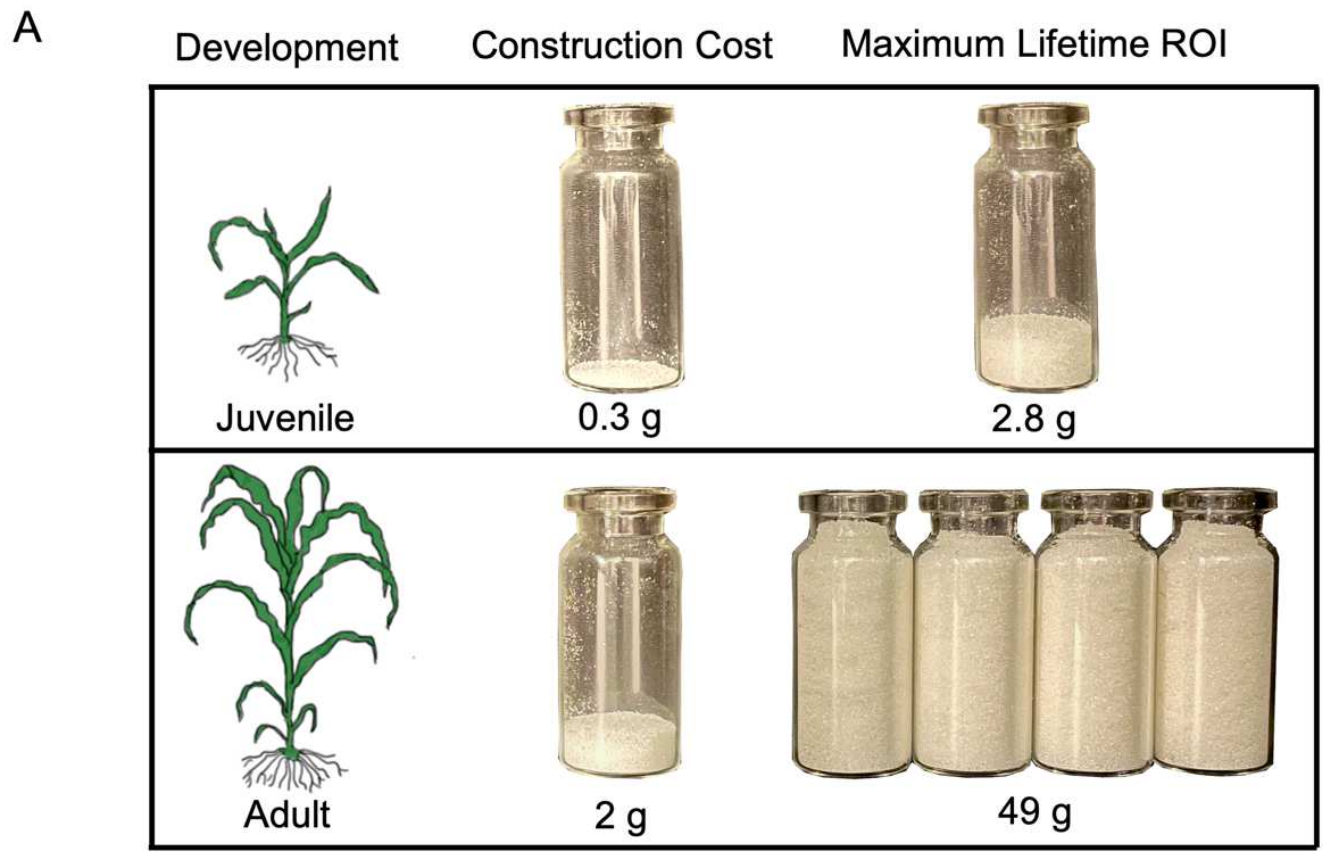

B

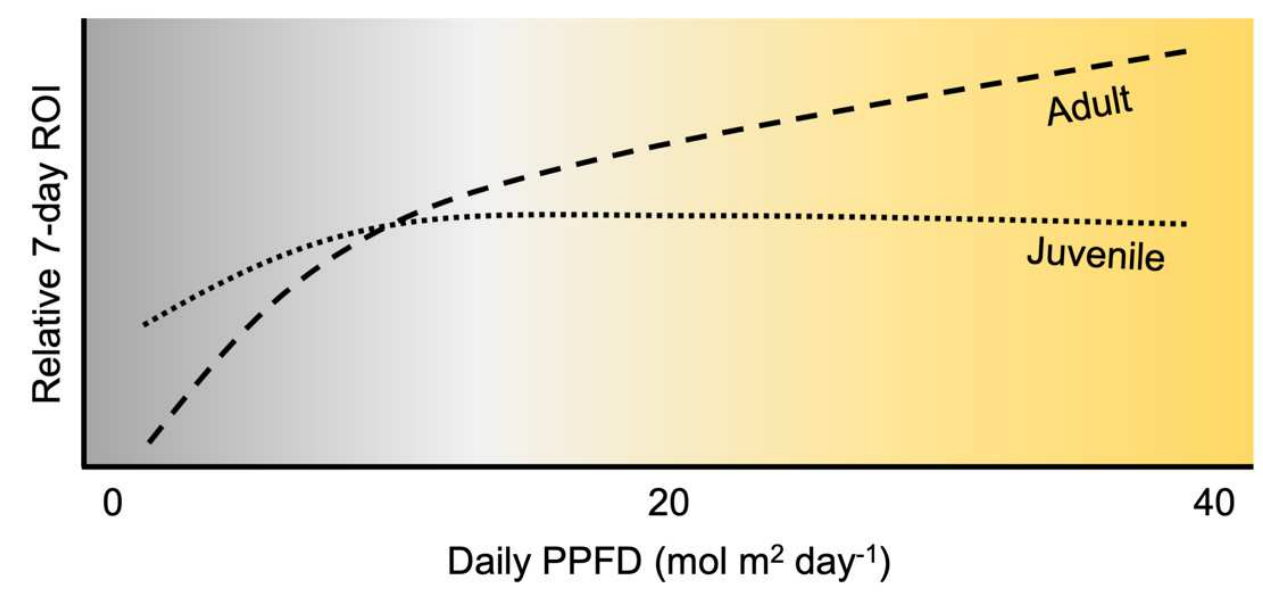

Figure 7. Juvenile leaves have a low-cost, low-return carbon economic strategy best suited for low-light environments while adult leaves have a high-cost, high-return strategy better suited for high light environments. Visual representations of the differences in construction cost and maximum lifetime return on investment (ROI), in grams of sugar, between juvenile and adult leaves of $Z$. mays (A). Maximum lifetime ROI was calculated using leaves photosynthesizing at light saturated photosynthetic rates for 12 hours a day during their full lifespan. Panel B shows the relative 7-day ROI for juvenile and adult leaves of $Z$. mays across light environments, 641 depicting the advantage for the juvenile strategy in low-light $\left(<10 \mathrm{~mol} \mathrm{~m}^{2}\right.$ day $\left.^{-1}\right)$ and adult leaves in high-light environments. 
644 Supplemental Tables

645

646 Table S1. Leaf morphological traits

647 Table S2. Light response curve parameters

648 Table S3. Light induction parameters

649 Table S4. Linear relationships for carbon economic traits in simulated dynamic light

650 environments

651 Table S5. Inputs for each dynamic light simulation

652

\section{Supplemental Figures}

654

655 Figure S1. Per-gram leaf tissue payback time and return on investment relationships with daily 656 light

657 Figure S2. Dynamic light environment simulations

658 Figure S3. Per-gram leaf tissue payback time and return on investment for $P$. tremula $x$ alba

659 from simulated dynamic light environments

660 Figure S4. Per-gram leaf tissue payback time and return on investment for Z. mays from 661 simulated dynamic light environments 
Figures

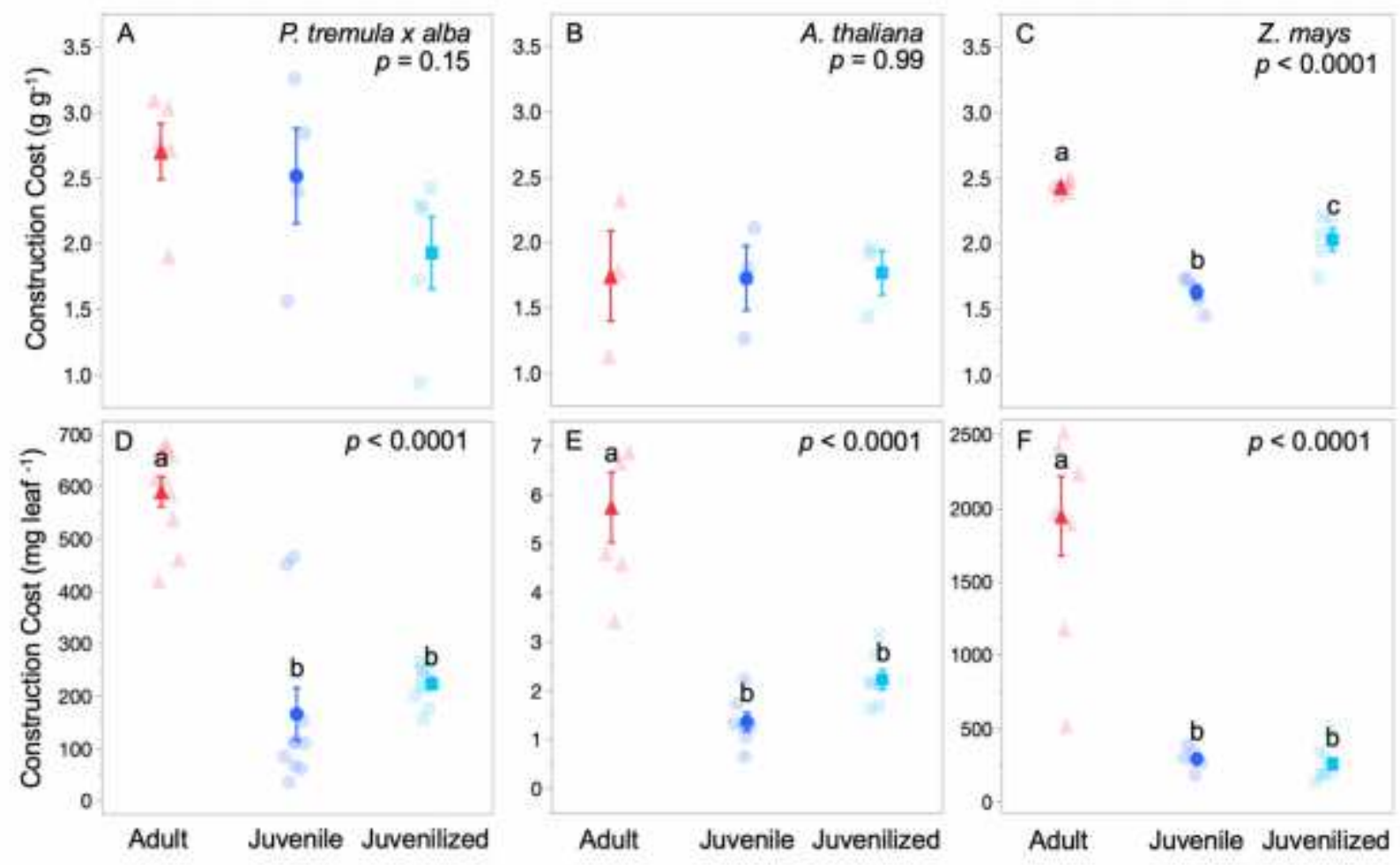

\section{Figure 1}

Please see the manuscript file to view the figure caption. 

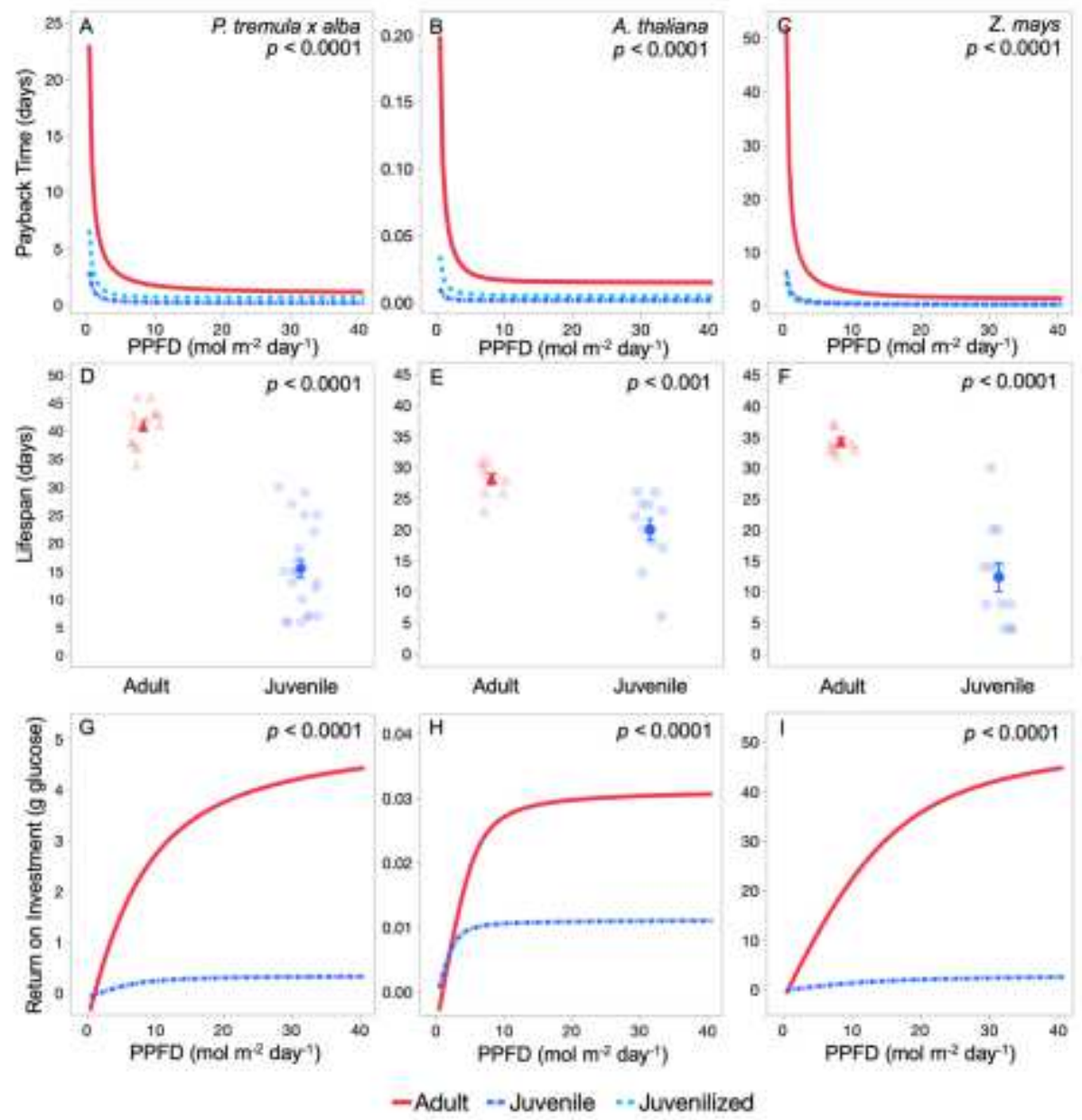

Figure 2

Please see the manuscript file to view the figure caption. 

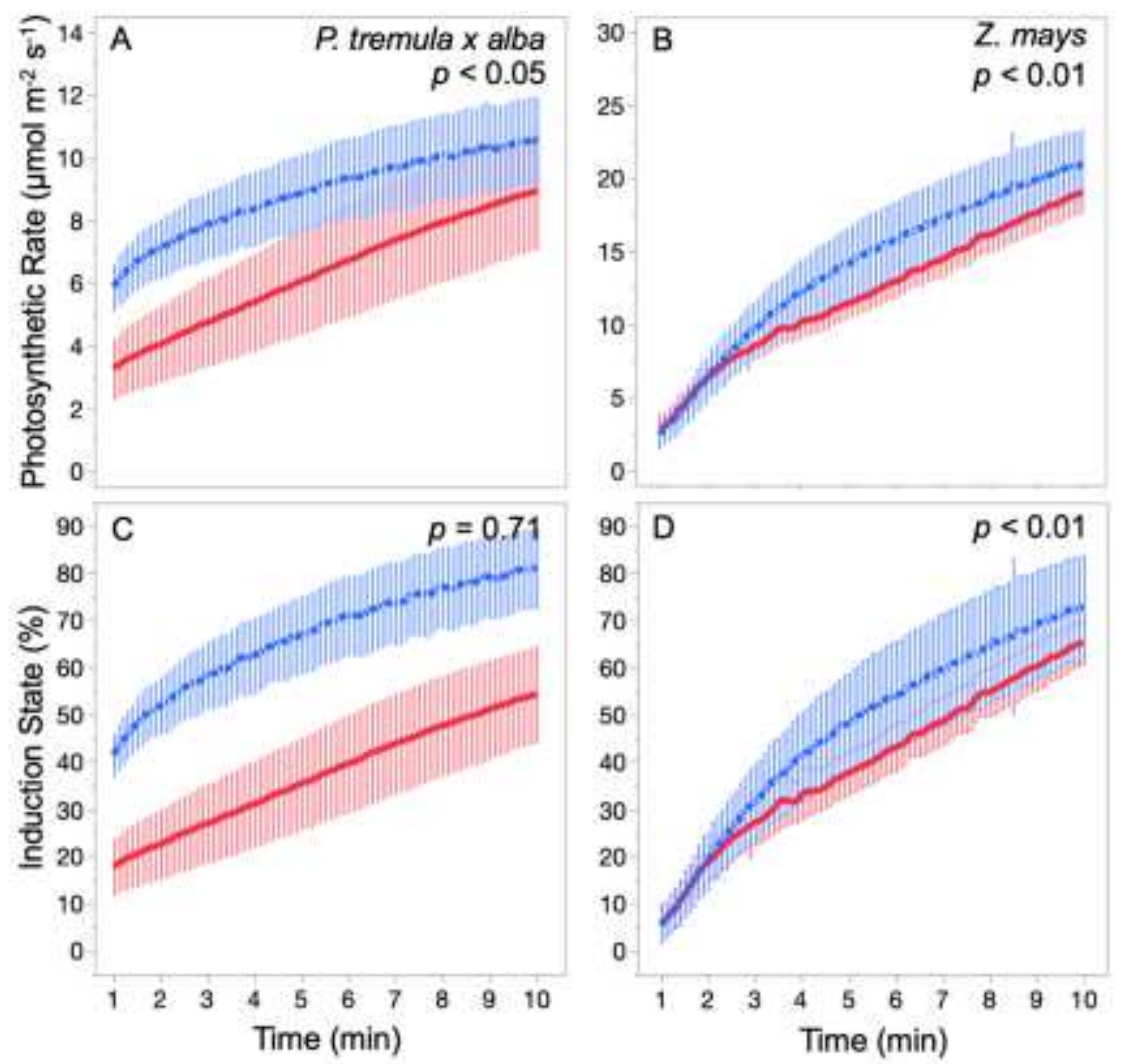

-Adult -.. Juvenile

\section{Figure 3}

Please see the manuscript file to view the figure caption. 


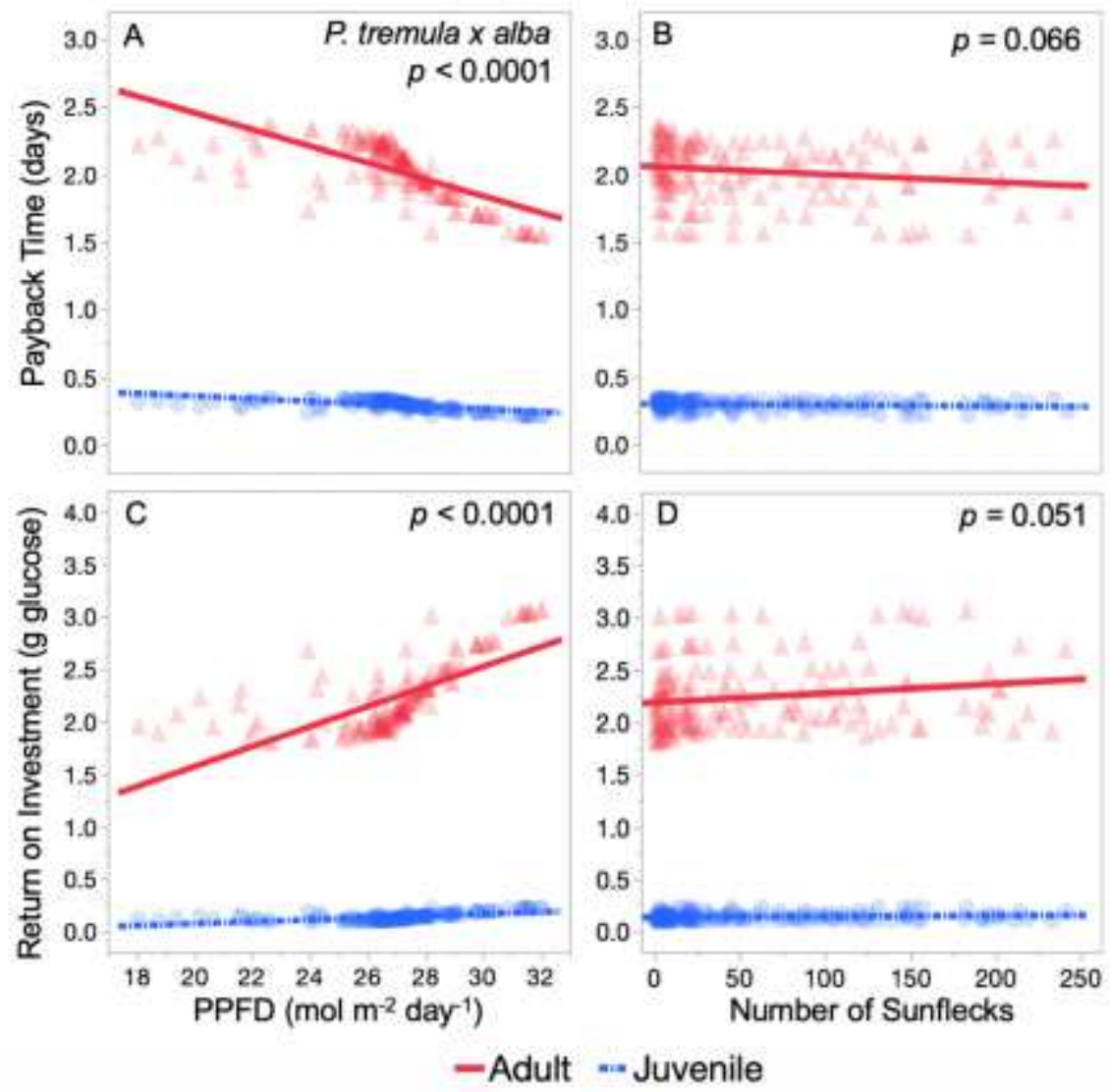

Figure 4

Please see the manuscript file to view the figure caption. 

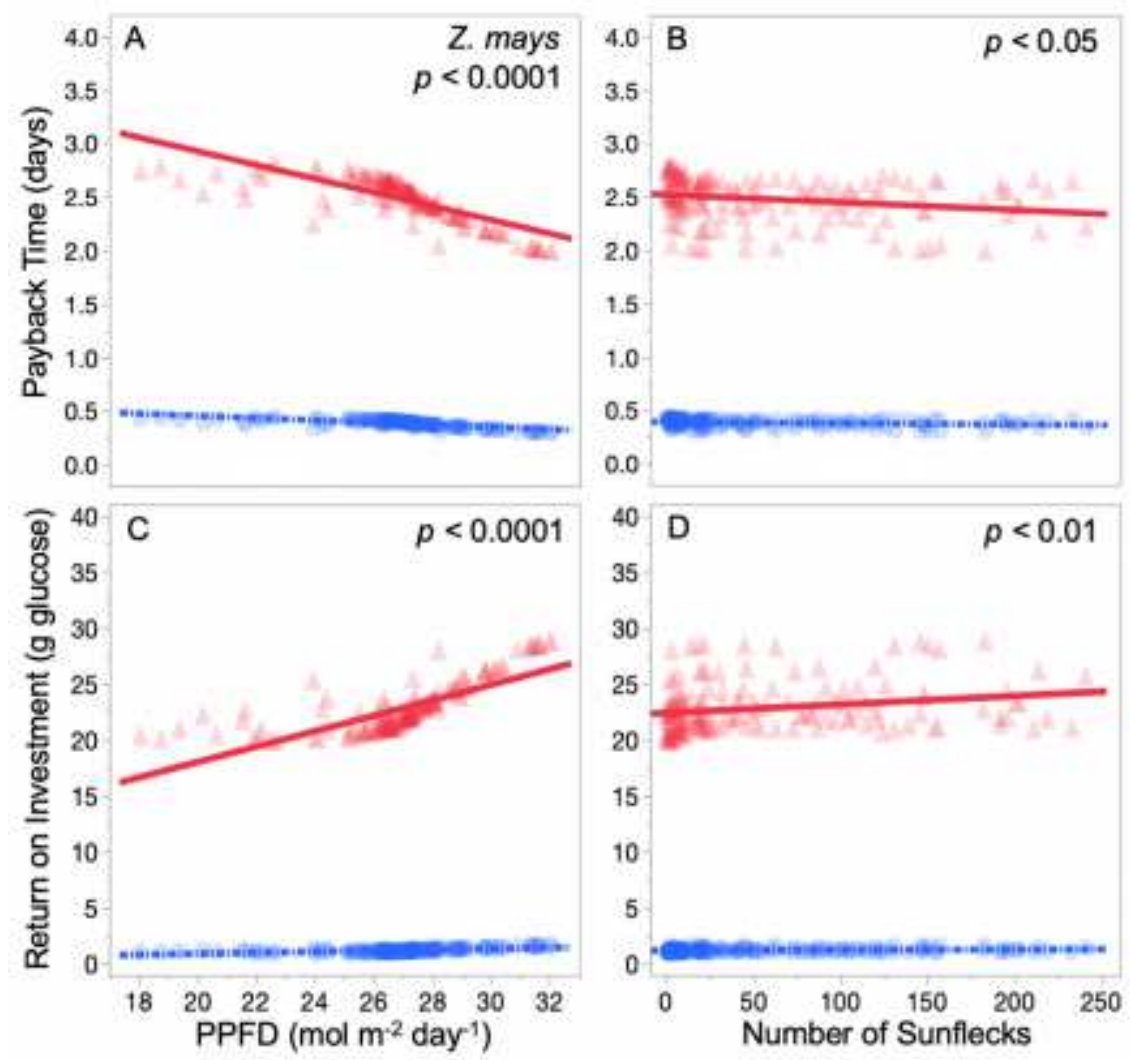

-Adult *is Juvenile

\section{Figure 5}

Please see the manuscript file to view the figure caption.

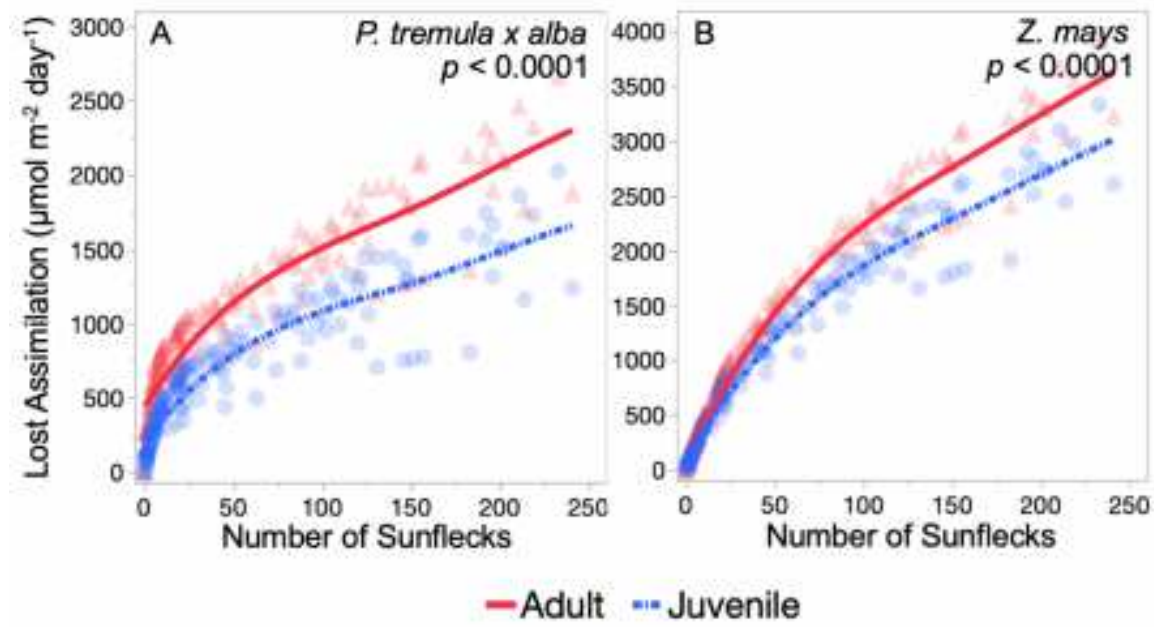

Figure 6

Please see the manuscript file to view the figure caption. 
A

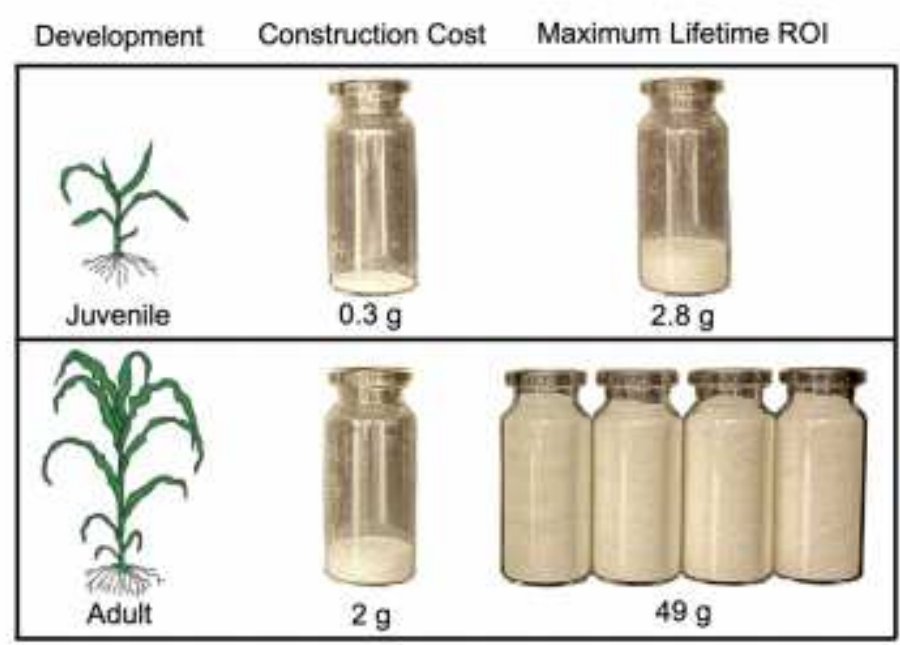

B

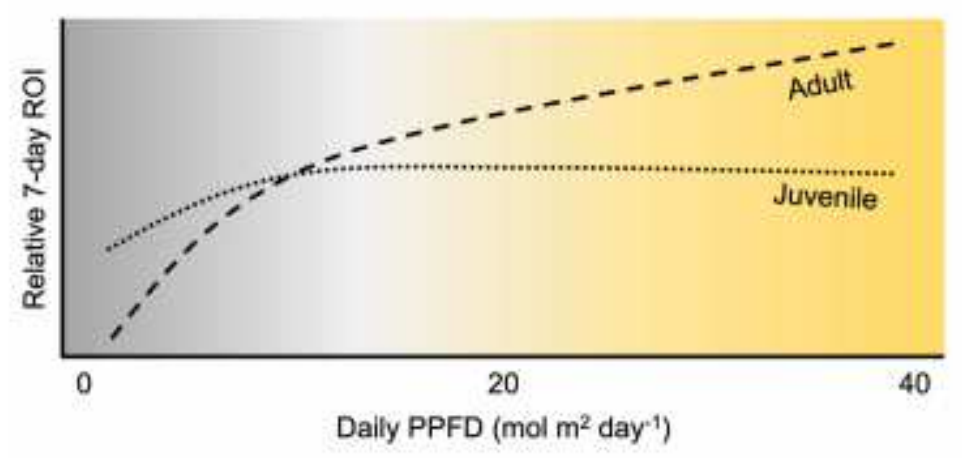

Figure 7

Please see the manuscript file to view the figure caption.

\section{Supplementary Files}

This is a list of supplementary files associated with this preprint. Click to download.

- Appendixequations.pdf

- Supplement.pdf 